\title{
Evaluation of five dry particle deposition parameterizations for incorporation into atmospheric transport models
}

\author{
Tanvir R. Khan and Judith A. Perlinger \\ Department of Civil and Environmental Engineering, Michigan Technological University, Houghton, MI 49931, USA
}

Correspondence to: Judith A. Perlinger (jperl@ mtu.edu)

Received: 6 April 2017 - Discussion started: 1 June 2017

Revised: 30 August 2017 - Accepted: 14 September 2017 - Published: 25 October 2017

\begin{abstract}
Despite considerable effort to develop mechanistic dry particle deposition parameterizations for atmospheric transport models, current knowledge has been inadequate to propose quantitative measures of the relative performance of available parameterizations. In this study, we evaluated the performance of five dry particle deposition parameterizations developed by Zhang et al. (2001) (“Z01”), Petroff and Zhang (2010) ("PZ10"), Kouznetsov and Sofiev (2012) ("KS12"), Zhang and He (2014) ("ZH14"), and Zhang and Shao (2014) ("ZS14"), respectively. The evaluation was performed in three dimensions: model ability to reproduce observed deposition velocities, $V_{\mathrm{d}}$ (accuracy); the influence of imprecision in input parameter values on the modeled $V_{\mathrm{d}}$ (uncertainty); and identification of the most influential parameter(s) (sensitivity). The accuracy of the modeled $V_{\mathrm{d}}$ was evaluated using observations obtained from five land use categories (LUCs): grass, coniferous and deciduous forests, natural water, and ice/snow. To ascertain the uncertainty in modeled $V_{\mathrm{d}}$, and quantify the influence of imprecision in key model input parameters, a Monte Carlo uncertainty analysis was performed. The Sobol' sensitivity analysis was conducted with the objective to determine the parameter ranking from the most to the least influential. Comparing the normalized mean bias factors (indicators of accuracy), we find that the ZH14 parameterization is the most accurate for all LUCs except for coniferous forest, for which it is second most accurate. From Monte Carlo simulations, the estimated mean normalized uncertainties in the modeled $V_{\mathrm{d}}$ obtained for seven particle sizes (ranging from 0.005 to $2.5 \mu \mathrm{m}$ ) for the five LUCs are 17, 12, 13, 16, and $27 \%$ for the Z01, PZ10, KS12, ZH14, and ZS14 parameterizations, respectively. From the Sobol' sensitivity results, we suggest that the parameter rankings vary by particle size and LUC for a given parameteriza-
\end{abstract}

tion. Overall, for $d_{\mathrm{p}}=0.001$ to $1.0 \mu \mathrm{m}$, friction velocity was one of the three most influential parameters in all parameterizations. For giant particles $\left(d_{\mathrm{p}}=10 \mu \mathrm{m}\right)$, relative humidity was the most influential parameter. Because it is the least complex of the five parameterizations, and it has the greatest accuracy and least uncertainty, we propose that the ZH14 parameterization is currently superior for incorporation into atmospheric transport models.

\section{Introduction}

Dry deposition is a complex process that is influenced by the chemical properties of aerosols and their sources, meteorological conditions, and surface characteristic features. The transference of particles from the atmosphere to the Earth's surface is controlled by forcings such as frictional drag and terrain-induced flow modification (Giorgi, 1986; Stull, 2012). Understanding the processes and factors controlling dry deposition is necessary to estimate the residence time of atmospheric particles, which governs their atmospheric transport distance, transboundary fluxes, and potential climate effects (IPCC, 2001; Nemitz et al., 2002; Pryor et al., 2008). An accurate estimation of dry deposition is also needed to quantify the atmospheric loads of particles containing sulfate, nitrate, and ammonium that contribute to acidification and eutrophication of ecosystems, toxic elements such as $\mathrm{Pb}, \mathrm{Zn}$, and $\mathrm{Cd}$, and base cations such as $\mathrm{Na}^{+}, \mathrm{K}^{+}, \mathrm{Ca}^{2+}$, and $\mathrm{Mg}^{2+}$ that alter the nutrient cycling in soil (Ruijgrok et al., 1995; Petroff et al., 2008a).

Over the last three decades, several indirect and direct methods were developed to measure dry particle deposition (hereinafter referred to as dry deposition) flux to ecosystems 
(McMahon and Denison, 1979; Sehmel, 1980; Gallagher et al., 1997; Zhang and Vet, 2006; Pryor et al., 2008). Dry deposition velocity $V_{\mathrm{d}}$ at height $z$ is defined as the ratio of the total flux $F(z)$ divided by the particle concentration at the same height $C(z)$ (Pryor et al., 2013; Rannik et al., 2016) and is mathematically expressed as

$V_{\mathrm{d}}=-\frac{F(z)}{C(z)}$.

One of the major limitations of direct flux measurement is limited spatial coverage because the measurement stations are confined to only a limited number of sites (Nemitz et al., 2002). The application of spatially and temporally resolved 3-D atmospheric transport models, from regional to global scale, can produce estimates of dry deposition fluxes for a suite of atmospheric species over various natural surfaces such as bare soil, grass, forest canopies, water, and ice/snow. To predict the dry deposition fluxes using atmospheric transport models, a parameterization/scheme that can adequately account for the major physical processes of particle deposition (e.g., turbulent diffusion, gravitational settling, interception, impaction, and Brownian diffusion) must be embedded in the host model.

Many dry deposition models have been developed for scientific research and operational purposes (see model review by Petroff et al., 2008a). Significant advances in understanding the governing mechanisms of dry deposition were made through use of experimental deposition data on walls of vertical pipes in the developments of size-resolved parameterizations for atmospheric particle deposition on ground surface (Muyshondt et al., 1996; Noll et al., 2001; Feng, 2008). In mechanistic or process-based dry deposition models, an electrical resistance-based approach is widely used to parameterize the dry deposition velocity (Venkatram and Pleim, 1999). In this approach, dry deposition occurs via two parallel pathways: turbulent diffusion (expressed as aerodynamic resistance) and gravitational settling (expressed as resistance due to gravitation). In addition, particle collection by surfaces via Brownian diffusion, interception, and impaction is represented using separate surface resistance terms (Slinn, 1982; Hicks et al., 1987; Wesely and Hicks, 2000; Zhang et al., 2001; Seinfeld and Pandis, 2006; Petroff and Zhang, 2010; Zhang and He, 2014). In all these models, the conventional resistance-based approach does not consider surface inhomogeneity or terrain complexity (i.e., deposition over flat terrain is assumed). However, Hicks (2008) argued about the importance of considering terrain complexity in dry deposition models because the assumption of surface homogeneity in existing deposition models limits the accuracy of pollutant load estimation in sensitive ecosystems that are located in complex terrain (e.g., on mountaintops or hills).

Despite considerable efforts in developing dry deposition parameterizations of varying complexity, there remain considerable gaps in systematic performance evaluation of existing schemes with reliable field measurements. We note that the evaluation of dry deposition parameterizations with field measurements is very limited and not up to date. Van Aalst (1986) evaluated the performance of six dry deposition parameterizations against field measurements and reported large discrepancies in terms of the modeled deposition velocities. He reported that over water surfaces the modeled deposition velocities for $1.0 \mu \mathrm{m}$ particles by the Williams (1982) scheme were factors of 10 to 50 higher than those predicted by the Sehmel and Hodgson (1978) scheme. For forest canopy, the Wiman and Ågren (1985) model overpredicted the deposition velocities of the Slinn (1982) model by a factor of 5. In a recent study, Hicks et al. (2016) compared five deposition models with measurements conducted over forests. They found that for particle sizes less than approximately $0.2 \mu \mathrm{m}$, the modeled deposition velocities agreed fairly well with measured velocities. The largest discrepancy was observed for particle sizes of 0.3 to approximately $5.0 \mu \mathrm{m}$. Studies also suggest that in many dry deposition parameterizations, the largest uncertainty exists for 0.1$1.0 \mu \mathrm{m}$ particles because of the differing treatments of some key particle deposition processes such as Brownian diffusion (Van Aalst, 1986; Petroff and Zhang, 2010; Zhang and Shao, 2014).

Uncertainty in modeled dry deposition velocities is an area that requires a thorough investigation. Only a few studies have been conducted in quantifying the uncertainties in dry deposition parameterizations. Ruijgrok (1992) performed an uncertainty evaluation of the Slinn (1982) model by assessing the variabilities in nine input parameters to the model outputs. Using Slinn's model, Gould and Davidson (1992) determined the influence of uncertainties in the size of the collection elements, roughness length, canopy wind profile, and wind speed on the modeled deposition velocities. As far as we know, a detailed uncertainty analysis to address the influence of varying particle size, meteorological conditions, and surface features has not been performed on existing dry deposition parameterizations. The results from an uncertainty analysis could be used as one of the model's performance indicators and help guide the modeling community to adequately account for uncertainties in the modeled deposition fluxes of pollutants to ecosystems.

Sensitivity analysis is often performed to determine the most influential parameters to the model outputs. Typically, a dry deposition model incorporates a large number of input parameters, which are subject to variability. In addition to identifying the most sensitive parameter(s), a sensitivity analysis can provide important insight as to the processes that control the overall deposition process and identify those that may require further improvement. However, a detailed sensitivity test that encompasses exploring the entire parameter spaces of the input parameters of a dry deposition parameterization has not yet been performed. Some researchers conducted one-at-a-time (OAT) sensitivity analysis (SA) (Ruijgrok et al., 1997; Zhang et al., 2001) of dry deposition models. In OAT-SA, the effect of varying one model input param- 
eter is tested at a time while keeping all others fixed (Saltelli and Annoni, 2010). Because in reality the variabilities in a set of model input parameters are expected to occur simultaneously, an OAT-SA is not a useful tool to determine the most influential parameter(s) in the deposition models. Rather, a variance-based global sensitivity test approach is needed. In global sensitivity analysis, the potential effects from simultaneous variabilities of model input parameters over their plausible range is considered (Lilburne and Tarantola, 2009).

In the present study, five dry deposition parameterizations, developed by Zhang et al. (2001), Petroff and Zhang (2010), Kouznetsov and Sofiev (2012), Zhang and He (2014), and Zhang and Shao (2014), are selected for an intercomparison of performance in terms of accuracy, uncertainty, and sensitivity. Throughout this paper, these models are referred to as Z01, PZ10, KS12, ZH14, and ZS14, respectively. The objectives of this study are threefold. The first objective is to evaluate the accuracy of five dry deposition parameterizations using measured dry deposition velocities obtained from field observations. Data of measured deposition velocities were collected from the literature, which was comprised of measurements conducted over land use categories (LUCs) including grass, coniferous and deciduous forests, natural water, and ice/snow. The second objective is to perform an uncertainty analysis of the modeled dry deposition velocities related to imprecision in model input parameter values. The third objective is to quantify the most influential parameters in the modeled dry deposition velocities by applying a global variance-based sensitivity analysis.

\section{Background}

The five dry deposition schemes used in this paper are described briefly below. For each scheme, the major expressions/equations used to compute the dry deposition velocities are provided.

\subsection{Zhang et al. (2001) (Z01) scheme}

The Z01 scheme estimates dry deposition velocity as a function of particle size and density, meteorological variables, and surface properties. In the Z01 scheme, the dry deposition velocity $\left(V_{\mathrm{d}}\right)$ is expressed as

$V_{\mathrm{d}}=V_{\mathrm{g}}+\frac{1}{R_{\mathrm{a}}+R_{\mathrm{s}}}$,

where $V_{\mathrm{g}}$ is the gravitational settling velocity, $R_{\mathrm{a}}$ is the aerodynamic resistance above the canopy, and $R_{\mathrm{S}}$ is the surface resistance. The expression for gravitational settling velocity $\left(V_{\mathrm{g}}\right)$ is given as

$V_{\mathrm{g}}=\frac{\rho d_{\mathrm{p}}^{2} g C}{18 \eta_{\mathrm{V}}}$,

where $\rho$ is the dry density of the particle, $d_{\mathrm{p}}$ is the particle aerodynamic diameter, $g$ is the gravitational accelera- tion, $C$ is the Cunningham correction factor, and $\eta_{\mathrm{V}}$ is the temperature-dependent viscosity coefficient of air. The correction factor $C$ is applied to account for the molecular structure of the air and is expressed as

$C=1+\frac{2 \lambda}{d_{\mathrm{p}}}\left(1.257+0.4 e^{-\frac{0.55 d_{\mathrm{p}}}{\lambda}}\right)$,

where $\lambda$ is the mean free path of air molecules.

The aerodynamic resistance $\left(R_{\mathrm{a}}\right)$ is calculated as

$R_{\mathrm{a}}=\frac{\ln \left(\frac{z_{\mathrm{R}}}{z_{0}}\right)-\psi_{\mathrm{H}}}{\kappa u_{*}}$,

where $z_{\mathrm{R}}$ is the reference height where $V_{\mathrm{d}}$ is typically computed, $z_{0}$ is the roughness height, $\kappa$ is the von Kármán constant, $u_{*}$ is the friction velocity, and $\psi_{\mathrm{H}}$ is the stability function for heat. The expression for $\psi_{\mathrm{H}}$ is $\psi_{H}=$ $2 \ln \left[0.5\left(1+(1-16 x)^{0.5}\right]\right.$ when $x \in[-2 ; 0]$, and $\psi_{H}=-5 x$ when $x \in[0 ; 1]$. Here, $x=z / L_{0}$, where $z$ is the measurement height and $L_{\mathrm{O}}$ is the Monin-Obukhov length.

The surface resistance term, $R_{\mathrm{S}}$ in Eq. (2), is a function of particle collection efficiencies due to Brownian diffusion $\left(E_{\mathrm{B}}\right)$, impaction $\left(E_{\mathrm{IM}}\right)$, and interception $\left(E_{\mathrm{IN}}\right)$. Accordingly, $R_{\mathrm{S}}$ is parameterized as

$R_{\mathrm{S}}=\frac{1}{\varepsilon_{0} u_{*}\left(E_{\mathrm{B}}+E_{\mathrm{IM}}+E_{\mathrm{IN}}\right) R_{1}}$,

where $\varepsilon_{0}$ is an empirical constant and its value is taken as 3 for all LUCs, and $R_{1}$ is the correction factor for particle rebound, which is included to modify the collection efficiencies at the surface. $R_{1}$ is parameterized as a function of Stokes number $(S t)$ as

$R_{1}=\exp \left(-S t^{-0.5}\right)$.

The parameterizations for $E_{\mathrm{B}}, E_{\mathrm{IM}}$, and $E_{\mathrm{IN}}$ are expressed by Eqs. (8), (10), and (14), respectively. The particle collection efficiency $\left(E_{\mathrm{B}}\right)$ is parameterized as a function of Schmidt number $(S c)$ as

$E_{\mathrm{B}}=S c^{-\gamma}$,

where $S c$ is the ratio of kinematic viscosity of air (v) to the particle Brownian diffusivity $(D) . \gamma$ is a LUC-dependent variable, and the typical values of $\gamma$ range from 0.54 to 0.56 for rough surfaces and from 0.50 to 0.56 for smooth surfaces. Brownian diffusivity $(D)$ is calculated as

$D=\frac{C k_{\mathrm{B}} T}{3 \pi \mu d_{\mathrm{p}}}$,

where $C$ is the Cunningham correction factor as expressed by Eq. (4), $k_{\mathrm{B}}$ is Boltzmann's constant $\left(1.38 \times 10^{-23} \mathrm{~J} \mathrm{~K}^{-1}\right)$, and $\mu$ is the dynamic viscosity of air at temperature $T$. 
For smooth surfaces, particle collection efficiency by impaction $\left(E_{\mathrm{IM}}\right)$ is parameterized as

$E_{\mathrm{IM}}=10^{-\frac{3}{S t}}$.

In addition, for rough surfaces,

$E_{\mathrm{IM}}=\left(\frac{S t}{\alpha+S t}\right)^{\beta}$,

where $\alpha$ and $\beta$ are constants; values of $\alpha$ are LUC dependent, and $\beta$ is taken as 2. In Eqs. (10)-(11), the Stokes number (St) is expressed as

$S t=\frac{V_{\mathrm{g}} u_{*}}{g A} \quad$ (for vegetative surfaces),

$S t=\frac{V_{\mathrm{g}} u_{*}^{2}}{v} \quad$ (for smooth surfaces),

where $A$ is the characteristic radius of the surface collector elements. The values of $A$ are given for different LUCs for various seasons by Zhang et al. (2001).

Collection efficiency by interception $\left(E_{\mathrm{IN}}\right)$ is calculated as

$E_{\mathrm{IN}}=\frac{1}{2}\left(\frac{d_{\mathrm{p}}}{A}\right)^{2}$.

Growth of particles under humid conditions is considered in the Z01 scheme by replacing the $d_{\mathrm{p}}$ with a wet particle diameter $\left(d_{\mathrm{w}}\right)$, which is calculated as

$d_{\mathrm{w}}=\left[\frac{C_{1}\left(\frac{d_{\mathrm{p}}}{2}\right)^{C_{2}}}{C_{3}\left(\frac{d_{\mathrm{p}}}{2}\right)^{C_{4}}-\log \mathrm{RH}}+\left(\frac{d_{\mathrm{p}}}{2}\right)^{C_{3}}\right]^{\frac{1}{3}}$,

where $C_{1}, C_{2}, C_{3}$, and $C_{4}$ are the empirical constants (values given in Table 1 of Zhang et al., 2001), and RH is the relative humidity.

\subsection{Petroff and Zhang (2010) (PZ10) scheme}

Petroff and Zhang (2010) parameterized dry deposition velocity using an expression similar to Eq. (2) with some improvements of the surface resistance and collection efficiency terms. In the PZ10 scheme, the effect of gravity and drift forces (e.g., phoretic effects) was taken into account by introducing the term drift velocity $\left(V_{\text {drift }}\right)$. Thus, dry deposition velocity $\left(V_{\mathrm{d}}\right)$ at a reference height $\left(z_{\mathrm{R}}\right)$ is given as

$V_{\mathrm{d}}=V_{\mathrm{drift}}+\frac{1}{R_{\mathrm{a}}+R_{\mathrm{s}}}$.

Here, the drift velocity $V_{\text {drift }}$ is equal to the sum of gravitational settling velocity and phoretic velocity, and the expression of $V_{\text {drift }}$ is

$V_{\text {drift }}=V_{\mathrm{g}}+V_{\text {phor }}$.
$V_{\mathrm{g}}$ is calculated using Eq. (3). The LUC-dependent values of $V_{\text {phor }}$ were given by Petroff and Zhang (2010).

Surface resistance $\left(R_{\mathrm{S}}\right)$ is commonly expressed as an inverse of the surface deposition velocity, $V_{\mathrm{ds}}$ (i.e., $R_{\mathrm{S}}=$ $\left.1 / V_{\mathrm{ds}}\right)$. In the PZ10 scheme, $V_{\mathrm{ds}}$ is parameterized as

$\frac{V_{\mathrm{ds}}}{u_{*}}=E_{\mathrm{g}} \frac{1+\left[\frac{Q}{Q_{\mathrm{g}}}-\frac{\alpha}{2}\right] \frac{\tanh (\eta)}{\eta}}{1+\left[\frac{Q}{Q_{\mathrm{g}}}+\alpha\right] \frac{\tanh (\eta)}{\eta}}$.

The parameters (e.g., $Q, Q_{\mathrm{g}}, \alpha$, and $\eta$ ) used in Eq. (18) are dependent on the aerodynamic and surface characteristic features. The parameterization of the total particle collection efficiency on the ground below the vegetation $\left(E_{\mathrm{g}}\right)$ has two components: (i) collection by Brownian diffusion $\left(E_{\mathrm{gb}}\right)$ and (ii) collection by turbulent impaction $\left(E_{\mathrm{gt}}\right)$. In the PZ10 scheme, formulation of $E_{\mathrm{gb}}$ is expressed as

$$
\begin{aligned}
E_{\mathrm{gb}}= & \frac{S c^{-\frac{2}{3}}}{14.5}\left[\frac{1}{6} \ln \frac{(1+F)^{2}}{1-F+F^{2}}+\frac{1}{\sqrt{3}} \operatorname{Arctan} \frac{2 F-1}{\sqrt{3}}\right. \\
& \left.+\frac{\pi}{6 \sqrt{3}}\right]^{-1},
\end{aligned}
$$

where $F$ is a function of the Schmidt number $(S c)$ and is expressed as $F=S c^{\frac{1}{3}} / 2.9$.

Collection efficiency by turbulent impaction, $E_{\mathrm{gt}}$, is a function of dimensionless particle relaxation time $\left(\tau_{\mathrm{ph}}^{+}\right)$and a coefficient $C_{\mathrm{IT}}$ (taken as 0.14 ). In the PZ10 scheme, $E_{\mathrm{gt}}$ is parameterized as

$E_{\mathrm{gt}}=2.5 \times 10^{-3} C_{\mathrm{IT}} \tau_{\mathrm{ph}}^{+2}$.

$\tau_{\mathrm{ph}}^{+}$is calculated as $\tau_{\mathrm{ph}}^{+}=\tau_{\mathrm{p}} u_{\mathrm{f}}^{2} / \nu$. The local friction velocity $\left(u_{\mathrm{f}}\right)$ is expressed as

$u_{\mathrm{f}}=u_{*} e^{-\alpha}$,

where $\alpha$ is the aerodynamic extinction coefficient and is expressed as

$\alpha=\left(\frac{k_{x} \mathrm{LAI}}{12 \kappa^{2}\left(1-\frac{d}{h}\right)^{2}}\right)^{\frac{1}{3}} \phi_{\mathrm{m}}^{\frac{2}{3}}\left(\frac{h-d}{L_{\mathrm{O}}}\right)$.

In Eq. (20), $k_{x}$ is the inclination coefficient of canopy elements, LAI is the leaf area index, $d$ is the zero-plane displacement height, $h$ is the height of the canopy, $L_{\mathrm{O}}$ is the Monin-Obukhov length, and $\phi_{\mathrm{m}}$ is the non-dimensional stability function for momentum. The expressions for $\phi_{\mathrm{m}}$ is $\phi_{\mathrm{m}}(x)=(1-16 x)^{-\frac{1}{4}}$ when $x \in[-2: 0]$ and $\phi_{\mathrm{m}}(x)=(1+$ $5 x)^{-\frac{1}{4}}$ when $x \in[0: 1]$.

In Eq. (18), the non-dimensional timescale parameter, $Q$, is defined as the ratio the turbulent transport timescale to the vegetation collection timescale. The magnitude of $Q$ can be used to characterize the dominant mechanism of the vertical 
transport of particles to the surface. For particle deposition over a canopy, $Q \ll 1$ describes a condition in which homogeneous concentration of Aitken and accumulation mode particles prevails throughout the canopy. This condition occurs when turbulent mixing is very efficient and transfer of particles is limited by the collection efficiency on leaves. In contrast, $Q \gg 1$ characterizes a situation in which an inhomogeneous particle concentration within the canopy prevails, which is typical for coarse mode particles. Under such conditions, efficient collection of particles by leaves takes place, and transfer to the surface is usually limited by the turbulent transport.

In the PZ10 scheme, $Q$ and $Q_{\mathrm{g}}$ are parameterized using Eqs. (23) and (24), respectively:

$$
\begin{gathered}
Q=\frac{\mathrm{LAI} E_{\mathrm{T}} h}{l_{\mathrm{mp}}(h)}, \\
Q_{\mathrm{g}}=\frac{E_{\mathrm{g}} h}{l_{\mathrm{mp}}(h)},
\end{gathered}
$$

where $E_{\mathrm{T}}$ is the total particle collection efficiency by various physical processes and $l_{\mathrm{mp}}(h)$ is the mixing height for the particles. The mixing height for particles, $l_{\mathrm{mp}}(h)$, is calculated as

$l_{\mathrm{mp}}(h)=\frac{\kappa(h-d)}{\phi_{\mathrm{h}}\left(\frac{h-d}{L_{\mathrm{O}}}\right)}$,

where $\phi_{\mathrm{h}}$ is the stability function for heat and expressed as $\phi_{\mathrm{h}}(x)=(1-16 x)^{-\frac{1}{2}}$ when $x \in[-2 ; 0]$ and $\phi_{\mathrm{h}}(x)=1+5 x$ when $x \in[0 ; 1]$.

The total collection efficiency $\left(E_{\mathrm{T}}\right)$ is expressed as

$E_{\mathrm{T}}=\frac{U_{\mathrm{h}}}{u_{*}}\left(E_{\mathrm{B}}+E_{\mathrm{IN}}+E_{\mathrm{IM}}\right)+E_{\mathrm{IT}}$,

where $U_{\mathrm{h}}$ is the horizontal wind speed at canopy height $h$, and $E_{\mathrm{B}}, E_{\mathrm{IN}}, E_{\mathrm{IM}}$, and $E_{\mathrm{IT}}$ are the collection efficiencies by Brownian diffusion, interception, impaction, and turbulent impaction, respectively. Note that the physical meanings of the first three efficiency terms are similar to those of the Z01 scheme. However, the parameterizations of these terms differ from the Z01 scheme. The term describing turbulent impaction efficiency $\left(E_{\mathrm{IT}}\right)$ is absent in the Z01 scheme.

Parameterizations of deposition efficiencies (i.e., $E_{\mathrm{B}}, E_{\mathrm{IN}}$, $E_{\mathrm{IM}}$, and $\left.E_{\mathrm{IT}}\right)$ are given below according to the PZ10 scheme.

Particle collection efficiency by Brownian diffusion $\left(E_{\mathrm{B}}\right)$ is given by

$E_{\mathrm{B}}=C_{\mathrm{B}} S c^{-\frac{2}{3}} R e_{\mathrm{h}}^{-\frac{1}{2}}$.

In Eq. (27), $C_{\mathrm{B}}$ is the LUC-dependent coefficient; $R e_{\mathrm{h}}$ is the Reynolds number of the horizontal air flow calculated at top of the canopy height $h$ as $\operatorname{Re}_{\mathrm{h}}=\frac{U_{\mathrm{h}} L}{v}$. Here, $L$ is the LUCdependent characteristic length of the canopy obstacle elements.
Particle collection efficiency by interception $\left(E_{\mathrm{IN}}\right)$ :

$E_{\mathrm{IN}}=C_{\mathrm{B}} \frac{d_{\mathrm{p}}}{L} \quad$ (for needle-like obstacle),

$E_{\mathrm{IN}}=C_{\mathrm{B}} \frac{d_{\mathrm{p}}}{L}\left[2+\ln \frac{4 L}{d_{\mathrm{p}}}\right]$ (for leaf of plane obstacle).

In Eqs. (28)-(29), $C_{\mathrm{B}}$ is the LUC-dependent coefficient.

Particle collection efficiency by impaction $\left(E_{\mathrm{IM}}\right)$ :

$E_{\mathrm{IM}}=C_{\mathrm{IM}}\left(\frac{S t_{\mathrm{h}}}{S t_{\mathrm{h}}+\beta_{\mathrm{IM}}}\right)^{2}$.

In Eq. (30), $S t_{\mathrm{h}}$ is the Stokes number on top of the canopy, which is calculated as $S t_{\mathrm{h}}=\frac{\tau_{\mathrm{p}} U_{\mathrm{h}}}{L} . \tau_{\mathrm{p}}$ is the particle relaxation time calculated as $\tau_{\mathrm{p}}=V_{\mathrm{g}} / g . C_{\mathrm{IM}}$ and $\beta_{\mathrm{IM}}$ are LUCdependent coefficients.

Particle collection efficiency by turbulent impaction $\left(E_{\mathrm{IT}}\right)$ is parameterized as

$$
\begin{aligned}
& E_{\mathrm{IT}}=2.5 \times 10^{-3} C_{\mathrm{IT}} \tau_{\mathrm{ph}}^{+2} \quad \text { if } \quad \tau_{\mathrm{ph}}^{+} \leq 20, \\
& E_{\mathrm{IT}}=C_{\mathrm{IT}} \quad \text { if } \quad \tau_{\mathrm{ph}}^{+} \geq 20 .
\end{aligned}
$$

In Eqs. (31)-(32), the dimensionless particle relaxation time is calculated as $\tau_{\mathrm{ph}}^{+}=\tau_{\mathrm{p}} u_{*}^{2} / \nu$.

The term $\eta$ in Eq. (18) is taken as

$\eta=\sqrt{\frac{\alpha^{2}}{4}}+Q$

For non-vegetative surfaces, such as bare soil, natural water and ice/snow, a modified form of Eq. (16) is used in the form of Eq. (34), which is expressed as

$V_{\mathrm{d}}=V_{\mathrm{drift}}+\frac{1}{R_{\mathrm{a}}+1 /\left(E_{\mathrm{gb}} u_{*}\right)}$.

\subsection{Kouznetsov and Sofiev (2012) (KS12) scheme}

Kouznetsov and Sofiev (2012) developed a dry deposition parameterization by extending the conventional resistancebased analogy using the exact solution of the steady-state equation for aerosol flux. According to the KS12 scheme, for rough surfaces, dry deposition velocity $\left(V_{\mathrm{d}}\right)$ is computed as

$V_{\mathrm{d}}=V_{\mathrm{diff}}+V_{\mathrm{int}}+V_{\mathrm{imp}}+V_{\mathrm{g}}$

where $V_{\text {diff }}, V_{\text {int }}, V_{\text {imp }}$, and $V_{\mathrm{g}}$ are the velocities for the depositing particles due to Brownian diffusion, interception, impaction, and gravitational settling, respectively. The parameterizations for these terms are provided below.

$V_{\text {diff }}$ was parameterized as

$V_{\mathrm{diff}}=2 u_{*} R e_{*}^{-\frac{1}{2}} S c^{-\frac{2}{3}}$, 
where $R e_{*}$ is the canopy Reynolds number given by

$R e_{*}=\frac{u_{*} a}{v}$,

where $a$ is the length scale for different LUCs.

$V_{\text {int }}$ is parameterized as

$V_{\mathrm{int}}=u_{*} R e_{*}^{\frac{1}{2}}\left(\frac{d_{\mathrm{p}}}{a}\right)^{2}$.

$V_{\text {imp }}$ is parameterized as

$V_{\mathrm{imp}}=\frac{2 u_{*}^{2}}{U_{\mathrm{top}}} \eta_{\mathrm{imp}}\left(S t-\frac{u_{*}}{U_{\mathrm{top}}} \operatorname{Re}_{*}^{-\frac{1}{2}}\right)$,

where $U_{\text {top }}$ is the mean horizontal wind speed on top of the canopy, $\eta_{\text {imp }}$ is the particle collection efficiency due to impaction, and $S t$ is the Stokes number. Kouznetsov and Sofiev (2012) used Eq. (40) to parameterize $\frac{u_{*}}{U_{\text {top }}}$ as

$\frac{u_{*}}{U_{\text {top }}}=\min \left[\left(C_{\mathrm{s}}+C_{\mathrm{R}} \mathrm{LAI} / 2\right)^{2},\left(\frac{u_{*}}{U_{\mathrm{top}}}\right)_{\max }\right]$,

where $C_{\mathrm{s}}=0.003, C_{\mathrm{R}}=0.3$, and $\left(\frac{u_{*}}{U_{\text {top }}}\right)_{\max }=0.3$ are constants.

The Stokes number $S t$ is expressed as

$S t=\frac{\tau_{\mathrm{p}} u_{*}}{a}$,

where $\tau_{\mathrm{p}}$ is the particle relaxation time calculated as $\tau_{\mathrm{p}}=$ $V_{\mathrm{g}} / g$.

The expression for $\eta_{\mathrm{imp}}$ is given as

$$
\begin{aligned}
& \eta_{\text {imp }}=\exp \left\{\frac{-0.1}{S t_{\mathrm{e}}-0.15}-\frac{1}{\sqrt{S t_{\mathrm{e}}-0.15}}\right\} \\
& \text { if } S t_{\mathrm{e}}>0.15, \\
& \eta_{\text {imp }}=0 \quad \text { if } \quad S t_{\mathrm{e}} \leq 0.15,
\end{aligned}
$$

where $S t_{\mathrm{e}}$ is the effective Stokes number calculated as

$S t_{\mathrm{e}}=S t-R e_{\mathrm{c}}^{-\frac{1}{2}}$,

where $R e_{\mathrm{c}}$ is the critical Reynolds number calculated as

$R e_{\mathrm{c}}=\left(\frac{U_{\mathrm{top}}}{u_{*}}\right)^{2} R e_{*}$.

The term $V_{\mathrm{g}}$ in Eq. (35) is parameterized using Eq. (3).

Note that, in the KS12 scheme, the parameterization of $V_{\mathrm{d}}$ over smooth surfaces requires solving the universal velocity profiles (either numerically or analytically) described by Kouznetsov and Sofiev (2012). We exclude the details of the solution procedure in this paper. We used the analytical solutions of the velocity profile obtained from the authors of the KS12 scheme through personal communication.

\subsection{Zhang and He (2014) (ZH14) scheme}

Zhang and He (2014) developed an empirical resistancebased parameterization for dry deposition by modifying the $\mathrm{Z} 01$ scheme. The overall structure of the ZH14 scheme is similar to that of the $\mathrm{Z} 01$ scheme (i.e., $V_{\mathrm{d}}$ is calculated using Eq. 2). In the ZH14 scheme, the parameterizations of $R_{\mathrm{a}}$ and $R_{\mathrm{g}}$ are similar to those of the Z01 scheme. However, in the ZH14 scheme, parameterizations for the surface resistance term $R_{\mathrm{S}}$ were modified for three bulk particle sizes (i.e., $\mathrm{PM}_{2.5}, \mathrm{PM}_{2.5-10}$, and $\mathrm{PM}_{10+}$ ). Recalling $R_{\mathrm{S}}=1 / V_{\mathrm{ds}}$, the parameterizations of $V_{\mathrm{ds}}$ are given below.

For particle sizes less than or equal to $2.5 \mu \mathrm{m}\left(\mathrm{PM}_{2.5}\right), V_{\mathrm{ds}}$ is expressed as

$V_{\mathrm{ds}(\mathrm{PM} 2.5)}=a_{1} u_{*}$,

where $a_{1}$ is an empirical constant derived by regression analysis. Values of $a_{1}$ are given by Zhang and He (2014) for five groups of 26 LUCs.

For particle sizes between 2.5 and $10 \mu \mathrm{m}\left(\mathrm{PM}_{2.5-10}\right), V_{\mathrm{ds}}$ is expressed as

$V_{\mathrm{ds}(\mathrm{PM} 2.5-10)}=\left(b_{1} u_{*}+b_{2} u_{*}^{2}+b_{3} u_{*}^{3}\right) e^{k 1\left(\frac{\mathrm{LAI}}{\mathrm{LAI} \max }-1\right)}$,

where $b_{1}, b_{2}$, and $b_{3}$ are LUC-dependent constants, $\mathrm{LAI}_{\max }$ is the maximum leaf area index for a given LUC, and $k 1$ is a constant, which is a function of $u_{*}$, and expressed as

$k 1=c_{1} u_{*}+c_{2} u_{*}^{2}+c_{3} u_{*}^{3}$,

where $c_{1}, c_{2}$, and $c_{3}$ are the LUC-dependent constants.

For particle sizes larger than $10 \mu \mathrm{m}\left(\mathrm{PM}_{10+}\right), V_{\mathrm{ds}}$ is expressed as

$V_{\mathrm{ds}(\mathrm{PM} 10+)}=\left(d_{1} u_{*}+d_{2} u_{*}^{2}+d_{3} u_{*}^{3}\right) e^{k 2\left(\frac{\mathrm{LAI}}{\mathrm{LAI} \max }-1\right)}$,

where $d_{1}, d_{2}$, and $d_{3}$ are the LUC-dependent constants, and $\mathrm{LAI}_{\max }$ is the maximum leaf area index for a given LUC. The parameter $k 2$ is a constant, which is a function of $u_{*}$, and is expressed as

$k 2=f_{1} u_{*}+f_{2} u_{*}^{2}+f_{3} u_{*}^{3}$,

where $f_{1}, f_{2}$, and $f_{3}$ are the LUC-dependent constants.

\subsection{Zhang and Shao (2014) (ZS14) scheme}

Zhang and Shao (2014) used an analytical solution of the steady-state flux equation to derive an expression to compute dry deposition velocity $V_{\mathrm{d}}$ as

$V_{\mathrm{d}}=\left(R_{\mathrm{g}}+\frac{R_{\mathrm{s}}-R_{\mathrm{g}}}{\exp \left(\frac{R_{\mathrm{a}}}{R_{\mathrm{g}}}\right)}\right)^{-1}$. 
For neutral atmospheric stability conditions, the parameterizations of $R_{\mathrm{a}}$ for rough and smooth surfaces are given in Eqs. (52) and (53), respectively:

$R_{\mathrm{a}}=\frac{S c_{\mathrm{T}}}{\kappa u_{*}} \ln \left(\frac{z-d}{h_{\mathrm{c}}-d}\right), \quad$ (rough surfaces)

$R_{\mathrm{a}}=\frac{B_{1} S c_{\mathrm{T}}}{\kappa u_{*}} \ln \left(\frac{z}{z_{0}}\right), \quad$ (smooth surfaces),

where $B_{1}$ is an empirical constant $(0.45)$, and $S c_{\mathrm{T}}$ is the turbulent Schmidt number expressed as

$S c_{\mathrm{T}}=\left(1+\frac{\alpha^{2} V_{\mathrm{g}}^{2}}{u_{*}^{2}}\right)$,

where $\alpha$ is a dimensionless coefficient taken as 1 .

The gravitational resistance term $R_{\mathrm{g}}$ is calculated as $R_{\mathrm{g}}=$ $1 / V_{\mathrm{g}}$. The parameterization of the surface resistance term $R_{\mathrm{S}}$ is given by Zhang and Shao (2014) as follows:

$$
\begin{aligned}
R_{\mathrm{S}}= & \left\{R V_{\mathrm{dm}}\left[\frac{E}{C_{\mathrm{d}}} \frac{\tau_{\mathrm{c}}}{\tau}+\left(1+\frac{\tau_{\mathrm{c}}}{\tau}\right) S c^{-1}+10^{\frac{-3}{T_{\mathrm{p}, \delta}^{+}}}\right]\right. \\
& \left.+V_{\mathrm{g}, \mathrm{w}}\right\}^{-1},
\end{aligned}
$$

where $R=\exp (-b \sqrt{S t})$, and $b$ is an empirical constant, $E$ is the total collection efficiency, $C_{\mathrm{d}}$ is the drag partition coefficient, $S c$ is the Schmidt number, $T_{\mathrm{p}, \delta}^{+}$is the dimensionless particle relaxation time near the surface, and $V_{\mathrm{g}, \mathrm{w}}$ is the gravitational settling velocity of particle after humidity correction. $\frac{\tau_{\mathrm{c}}}{\tau}$ is the ratio of the drag on the roof of the roughness element $\left(\tau_{\mathrm{c}}\right)$ to the total shear stress $(\tau)$ and is calculated as

$$
\frac{\tau_{\mathrm{c}}}{\tau}=\frac{\beta \lambda_{\mathrm{e}}}{1+\beta \lambda_{\mathrm{e}}},
$$

where $\beta$ is the ratio of the pressure-drag coefficient to friction-drag coefficient, and $\lambda_{\mathrm{e}}$ is the effective frontal area index. The parameter $\lambda_{\mathrm{e}}$ is a function of frontal area index or roughness density $(\lambda)$, and plane area index $(\eta)$. The expression of $\lambda_{\mathrm{e}}$ is

$\lambda_{\mathrm{e}}=\frac{\lambda}{(1-\eta)^{c_{2}}} \exp \left(-\frac{c_{1} \lambda}{(1-\eta)^{c_{2}}}\right)$,

where $c_{1}=6$ and $c_{2}=0.1$.

Equation (56) is used to compute $T_{\mathrm{p}, \delta}^{+}$as

$T_{\mathrm{p}, \delta}^{+}=\frac{T_{\mathrm{p}, \delta} u_{*}^{2}}{v}$,

where $T_{\mathrm{p}, \delta}$ is the particle relaxation time near the surface $\left(T_{\mathrm{p}, \delta}=V_{\mathrm{g}} / g\right)$.

$V_{\mathrm{dm}}$ is calculated using two separate expressions for rough and smooth surfaces, as expressed in Eqs. (59) and (60), respectively:

$V_{\mathrm{dm}}=\frac{u_{*}}{u_{\mathrm{a}} h_{\mathrm{c}}} \quad$ (for rough surfaces), where $u_{\mathrm{a}}$ is the horizontal air speed and $h_{\mathrm{c}}$ is the height of the roughness element.

$V_{\mathrm{dm}}=B_{2} u_{*} \quad$ (for smooth surfaces),

where $B_{2}$ is an empirical constant taken as 3 .

In Eq. (55), the total collection efficiency $(E)$ is comprised of collection efficiencies by Brownian diffusion $\left(E_{\mathrm{B}}\right)$, impaction $\left(E_{\mathrm{IM}}\right)$, and interception $\left(E_{\mathrm{IN}}\right)$. The parameterizations for each of these three terms are given below:

$E_{\mathrm{B}}=C_{\mathrm{B}} S c^{-\frac{2}{3}} R e^{n_{\mathrm{B}}-1}$,

where $C_{\mathrm{B}}$ and $n_{\mathrm{B}}$ are empirical parameter functions of flow regimes and are given by Zhang and Shao (2014).

$E_{\mathrm{IM}}=\left(\frac{S t}{0.6+S t}\right)^{2}$,

where $S t$ is the Stokes number and is expressed as $S t=$ $\tau_{\mathrm{p}} u_{*} / d_{\mathrm{c}}$. Here, $d_{\mathrm{c}}$ is the diameter of the surface collection element. Values of $d_{\mathrm{c}}$ are given by Zhang and Shao (2014) for various surfaces.

$E_{\mathrm{IN}}=A_{\text {in }} u_{*} 10^{-S t} \frac{2 d_{\mathrm{p}, \mathrm{w}}}{d_{\mathrm{c}}}$,

where $A_{\text {in }}$ is a surface-dependent micro-roughness characteristic element, and $d_{\mathrm{p}, \mathrm{w}}$ is the wet diameter of the particle.

\section{Methods}

\subsection{An evaluation of the dry deposition parameterizations}

To assess the accuracy of the five parameterizations, the modeled dry deposition velocities were compared with field measurements from both rough and smooth surfaces. The measurement studies conducted on various natural surfaces were collected from the literature. More specifically, the studies cited in the review article on particle flux measurements by Pryor et al. (2008) were collected to acquire the metadata on particle deposition. The availability of the measured and/or reported parameters (e.g., particle size and density, air temperature, relative humidity, horizontal wind speed, friction velocity, atmospheric stability parameter, canopy height, roughness height, zero-plane displacement height, and leaf area index) from these measurement studies was thoroughly investigated and compiled. It was found that many (approximately $50 \%$ ) of the studies cited by Pryor et al. (2008) did not report most of the aforementioned parameters necessary to run the parameterizations to perform a valid comparison between the model output and measurements. To reduce uncertainty, those studies were excluded from the parameterization accuracy evaluation. In addition, a literature search was performed in Web of Science ${ }^{\circledR}$ to find measurement studies 


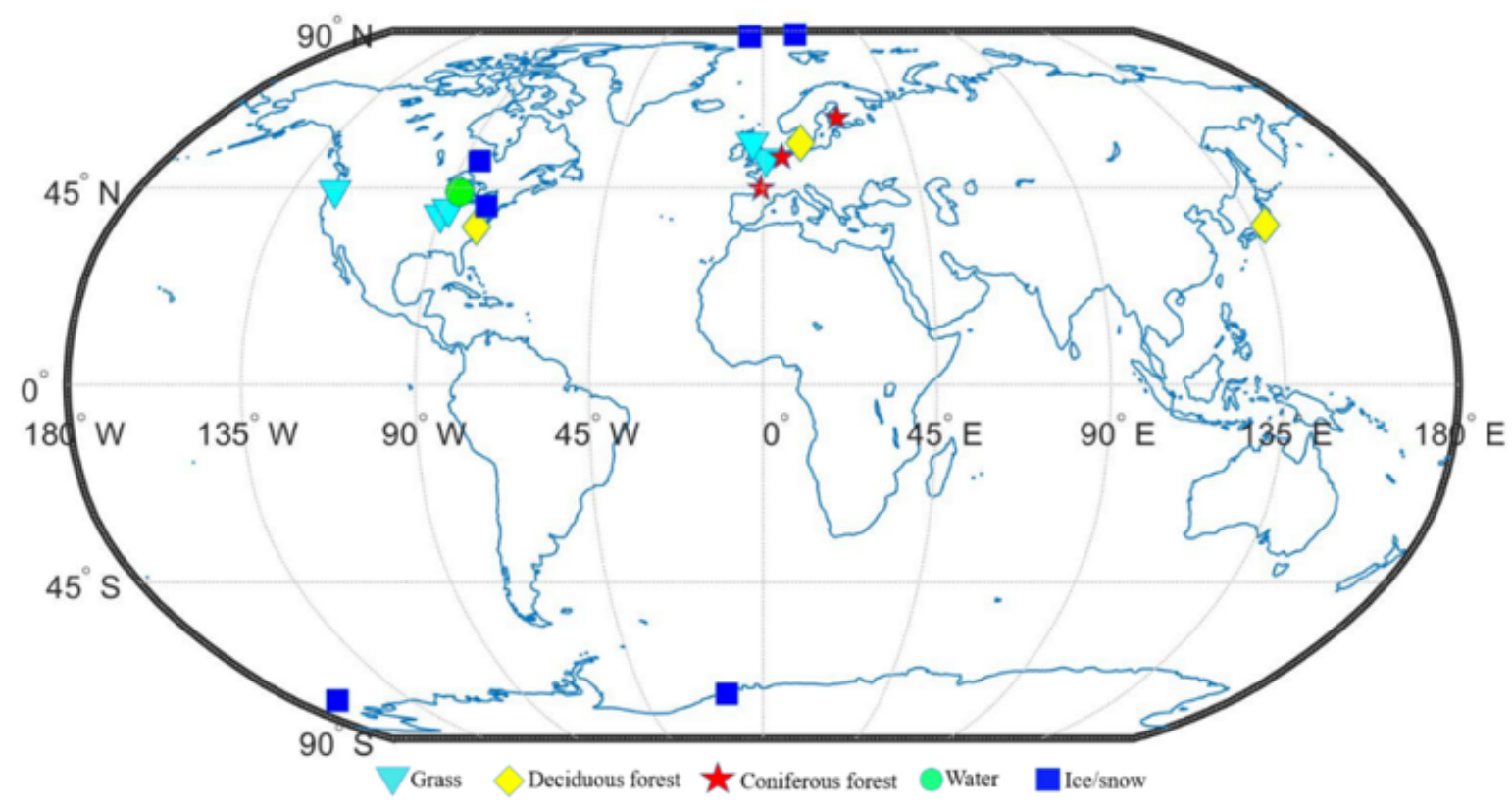

Figure 1. Global distribution of dry deposition measurement locations (listed in Table 1) used to evaluate the Z01, PZ10, KS12, ZH14, and ZS14 parameterizations. Note that for multiple measurement campaigns conducted in one location, only one data point is shown. Two wind tunnel studies on water surfaces are not shown.

published after 2008, and those studies were thoroughly assessed to determine the availability of required input parameters to run the dry deposition models. Finally, 29 measurement studies covering five LUCs were selected to evaluate the accuracy of the five parameterizations. The five LUCs include grass, deciduous and coniferous forests (rough surfaces), and natural water and ice/snow (smooth surfaces). Table 1 summarizes information related to sampling location, latitude, longitude, elevation above mean sea level (AMSL), sampling periods, and particle sizes reported in the measurement studies. The global spatial distribution of these measurement studies is shown in Fig. 1 according to the five LUCs.

Measurements conducted over grass by Wesely et al. (1977), Neumann and den Hartog (1985), Allen et al. (1991), Nemitz et al. (2002), and Vong et al. (2004) were used to evaluate the performance of the five parameterizations. For coniferous forest, modeled deposition velocities were compared with measurements from Lamaud et al. (1994), Wyzers and Duyzer (1996), Gallagher et al. (1997), Ruijgrok et al. (1997), Buzorius et al. (2000), Rannik et al. (2000), Gaman et al. (2004), Pryor et al. (2007), and Grönholm et al. (2009). Experiments conducted over deciduous forest are limited, and only three studies (Wesely et al., 1983; Pryor, 2006; Matsuda et al., 2010) were used in the present paper.

To evaluate the performance of the parameterizations over water surfaces, studies by Möller and Schumann (1970), Sehmel et al. (1974), Zufall et al. (1998), and Caffrey et al. (1998) were used. We note that the studies by Möller and Schumann (1970) and Sehmel et al. (1974) were conducted in the wind tunnels, and thus the observed deposition does not necessarily reflect deposition under natural conditions. Particle deposition measurements on ice/snow pack were collected from eight studies: Ibrahim et al. (1983), Duan et al. (1988), Nilsson and Rannik (2001), Gronlund et al. (2002), Contini et al. (2010), Held et al. (2011a, b), and Donateo and Contini (2014). The parameterizations were fed using reported values of particle properties (diameter and density), meteorological conditions (stability parameter, temperature, wind speed, etc.), and surface properties (canopy height, roughness length, leaf area index, etc.). However, reasonable values of the missing parameters were used when needed.

In the present study, the accuracy of the dry deposition parameterizations was evaluated using the normalized mean bias factor $\left(B_{\mathrm{NMBF}}\right)$. The $B_{\mathrm{NMBF}}$ provides a statistically robust and unbiased symmetric measure of the factor by which the modeled dry deposition velocities differ from the measured ones, and the sense of that factor (i.e., the positive and negative values imply the overprediction and underprediction by models, respectively). The interpretation of the $B_{\mathrm{NMBF}}$ is simple (i.e., average amount by which the ratio of modeled and measured quantities differs from unity), and it avoids any inflation that may be caused by low values of measured quantities (Yu et al., 2006).

To quantify the disagreement between the modeled and observed quantities, the normalized mean bias factors were 


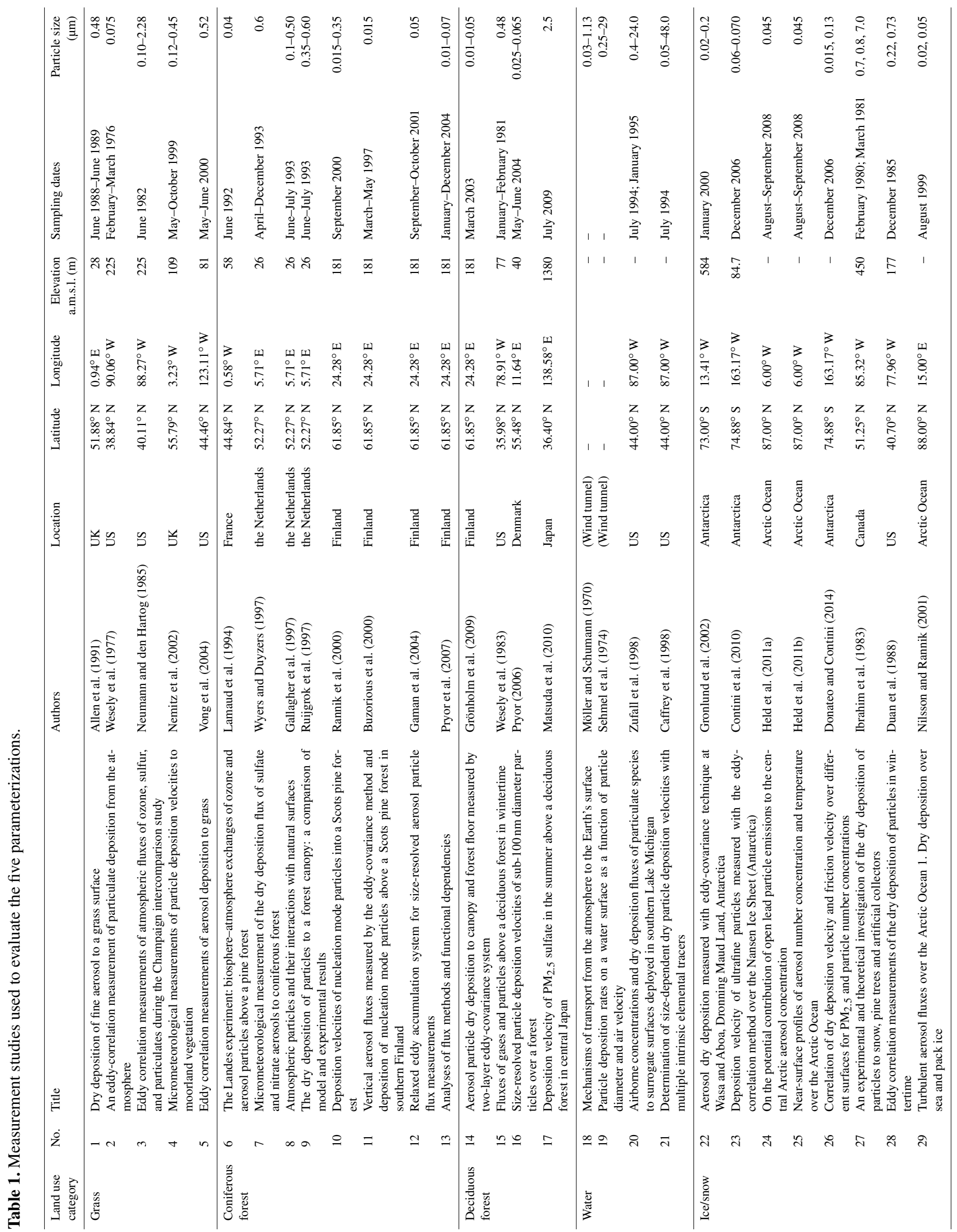


calculated for the pairs of modeled $\left(V_{\mathrm{d}(\text { modeled }), i}\right)$ and measured dry deposition velocities $\left(V_{\mathrm{d}(\text { measured }), i}\right)$, respectively. In this study, the expressions for computing $B_{\mathrm{NMBF}}$ used in two different forms, which are the following.

For the $V_{\mathrm{d}(\text { modeled), } i}>V_{\mathrm{d}(\text { measured) }, i}$ case (i.e., overestimation),

$B_{\mathrm{NMBF}}=\frac{\sum V_{\mathrm{d}(\text { modeled }), i}}{\sum V_{\mathrm{d}(\text { measured }), i}}-1$.

For the $V_{\mathrm{d}(\text { modeled), } i}<V_{\mathrm{d}(\text { measured), } i}$ case (i.e., underestimation),

$B_{\mathrm{NMBF}}=1-\frac{\sum V_{\mathrm{d}(\text { measured }), i}}{\sum V_{\mathrm{d}(\text { modeled }), i}}$.

The stepwise derivation of Eqs. (64)-(65) and their application in training air quality datasets are illustrated by $\mathrm{Yu}$ et al. (2006).

\subsection{Uncertainty analysis of the dry deposition parameterizations}

To quantify the influence of imprecision in the model input parameter values on the modeled velocities, a classical Monte Carlo uncertainty analysis was applied. The Monte Carlo techniques have been widely used to evaluate the propagated uncertainty in the modeled outputs in many geophysical models (e.g., Alcamo and Bartnickj, 1987; Derwent and Hov, 1988; Chen et al., 1997; Tatang et al., 1997; Hanna et al., 1998, 2001; Bergin et al., 1999; Bergin and Milford, 2000; Beekman and Derognat, 2003; Mallet and Sportisse, 2006). Monte Carlo uncertainty evaluation techniques are relatively straightforward and flexible means for incorporating probabilistic values in the modeled dry deposition velocities. Indeed, the techniques are less reliant on assumptions about distributions of the input parameters (Hanna et al., 2001).

In this study, we define uncertainty in the parameterizations as the inability to confidently specify single-valued quantities because of the imprecision in the model input parameters. A classical Monte Carlo uncertainty method was applied to assess the overall uncertainty of a dry deposition parameterization with regard to the uncertainties in the following input parameters: $\mathrm{RH}, h, z_{0}, d, \mathrm{LAI}, U, u_{*}$, and $L_{\mathrm{O}}$. The uncertainty estimates for those input parameters were obtained from the literature and are presented in Table 2. Using the uncertainty ranges for each of these parameters, uniform probability distribution functions were assigned since information on their actual distributions is lacking. It is noted that a constant dry particle density of $1500 \mathrm{~kg} \mathrm{~m}^{-3}$ (Petroff and Zhang, 2010) was used in all Monte Carlo simulations. Because of the inhomogeneous nature of ambient particles, accurate measurement of particle density is challenging. In their work, Oskouie et al. (2003) developed methods using a time-of-flight instrument to minimize the effect of uncertainties in density estimation in particle size characterization.
The Monte Carlo simulations were performed using R statistical software (version 3.2.4). Each simulation was run by randomly drawing 100 samples from the assigned uniform probability density function (PDF). The simulations were repeated 10000 times. Frequency distributions or the PDFs of the modeled dry deposition velocity are the basic results of the Monte Carlo simulations. These PDFs were approximated assuming normal distributions, and then the 5th, 50th, and 95th percentile dry deposition velocities were computed. We use the range of the central $90 \%$ (the difference between 95th and 5th percentiles) of the PDFs as a convenient measure of uncertainty in the modeled deposition velocity. These steps were repeated for all five parameterizations using seven different particle sizes: $0.005,0.05,0.5,1.0,1.5,2.0$, and $2.5 \mu \mathrm{m}$ on the five selected five LUCs (i.e., grass, deciduous and coniferous forests, water, and ice/snow). These particle sizes were selected to represent four distinct particle modes: nucleation $(<0.01 \mu \mathrm{m})$, Aitken $(0.01-0.1 \mu \mathrm{m})$, accumulation $(0.1-1.0 \mu \mathrm{m})$, and coarse $(>1.0 \mu \mathrm{m})$, respectively.

\subsection{Sensitivity analysis}

In this study, the Sobol' sensitivity method (Sobol', 1993) was applied to identify the most influential input parameter or the set of parameters of a dry deposition parameterization, and to characterize the relative contribution of the parameters to the overall variability in the modeled $V_{\mathrm{d}}$. As opposed to the local sensitivity analysis (e.g., OAT approach), the Sobol' method is a global sensitivity approach, in which a set of input parameters of a model can be varied simultaneously over their entire parameter value space to identify their relative contributions to the overall model output variance. The Sobol' method has been applied in environmental modeling applications (Tang et al., 2007; Pappenberger et al., 2008; van Werkhoven et al., 2008; Yang, 2011) but has not yet been applied in dry deposition modeling research. Given that in most of the dry deposition parameterizations, model inputs can span a wide range within their physical realms, the application of a global sensitivity analysis used in this study should be viewed as a critical step toward the understanding of different subphysical processes of particle deposition.

In the Sobol' method, the variance contributions to the total output variance of individual parameters and parameter interactions can be determined. These contributions are characterized by the ratio of the partial variance $\left(V_{i}\right)$ to the total variance $(V)$ as expressed in Eq. (66). This ratio is commonly termed as Sobol' first-order index $\left(S_{\mathrm{i}}\right)$ (Saltelli et al., 2010; Nossent et al., 2011). The first-order indices represent the fractions of the unconditional model output variance. In this study, Sobol' first-order sensitivity indices were calculated as

$S_{\mathrm{i}}=\frac{V_{i}}{V}=\frac{V_{X_{i}}\left(E_{\mathbf{X}_{\sim i}}\left(V_{\mathrm{d}} \mid X_{i}\right)\right)}{V\left(V_{\mathrm{d}}\right)}$,

where $X_{i}$ is the $i$ th input parameter and $\mathbf{X}_{\sim_{i}}$ denotes the matrix of all input parameters but $X_{i}$. The meaning of the inner 
Table 2. Parameter values and associated uncertainties used in Monte Carlo simulation.

\begin{tabular}{|c|c|c|c|}
\hline Parameter & Base value (assumed) & Uncertainty & Reference* $^{*}$ \\
\hline Relative humidity, RH (\%) & 80 (all LUCs) & $\pm 5 \%$ & Heinonen (2002) \\
\hline Wind speed, $U\left(\mathrm{~m} \mathrm{~s}^{-1}\right)$ & 4 (all LUCs) & $\pm 3 \%$ & Högström and Smedman (2004) \\
\hline Friction velocity, $u_{*}\left(\mathrm{~m} \mathrm{~s}^{-1}\right)$ & 0.3 (all LUCs) & $\pm 10 \%$ & Andreas (1992) \\
\hline Monin-Obukhov length, $L_{\mathrm{O}}(\mathrm{m})$ & 50 (all LUCs) & $\pm 10 \%$ & Weidinger et al. (2000) \\
\hline Roughness length, $z_{0}(\mathrm{~m})$ & $\begin{array}{l}0.04 \text { (grass) } \\
1.2 \text { (coniferous forest) } \\
1.5 \text { (deciduous forest) } \\
0.001 \text { (ice/snow) }\end{array}$ & $\pm 25 \%$ & Su et al. (2001) \\
\hline Canopy height, $h(\mathrm{~m})$ & $\begin{array}{l}0.5 \text { (grass) } \\
15 \text { (coniferous forest) } \\
25 \text { (dciduous forest) }\end{array}$ & $\pm 5 \%$ & Larjavaara and Muller-Landau (2013) \\
\hline Zero-plane displacement height, $d(\mathrm{~m})$ & $\begin{array}{l}0.3 \text { (grass) } \\
7 \text { (coniferous forest) } \\
16 \text { (deciduous forest) }\end{array}$ & $\pm 25 \%$ & Su et al. (2001) \\
\hline Leaf area index (one-sided), LAI $\left(\mathrm{m}^{2} \mathrm{~m}^{-2}\right)$ & $\begin{array}{l}4 \text { (grass) } \\
10 \text { (coniferous forest) } \\
10 \text { (deciduous forest) }\end{array}$ & $\pm 5 \%$ & Richardson et al. (2011) \\
\hline
\end{tabular}

* The references are for the uncertainty values (in percentage).

expectation operator is that the mean of $V_{\mathrm{d}}$ is taken over all possible values of $\mathbf{X}_{\sim i}$ while keeping $X_{i}$ fixed. The outer variance is taken over all possible values of $X_{i}$. The variance $V\left(V_{\mathrm{d}}\right)$ in the denominator is the total (unconditional) variance.

The numerator in Eq. (66) can be interpreted as follows: $V_{X_{i}}\left(E_{\mathbf{X}_{\sim i}}\left(V_{\mathrm{d}} \mid X_{i}\right)\right)$ is the expected reduction in variance that would be obtained if $X_{i}$ could be fixed. In regard to the variability of the model input parameters in dry deposition schemes, $S_{\mathrm{i}}$ provides a means to quantify the effect of parameter $X_{i}$ by itself. A higher order $\left(S_{\mathrm{i} j}\right)$ or total order $\left(S_{\mathrm{Ti}}\right)$ can be computed when the total effect of a parameter, inclusive of all its interaction with other model input parameters, is of interest. In this paper, we confine the sensitivity analysis to Sobol' first-order indices only.

For each of the five parameterizations evaluated here, four to nine input parameters were selected for determining the first-order Sobol' sensitivity indices. An exception to applying the Sobol' method was made for the KS12 parameterization while evaluating the parameter sensitivity for smooth surfaces. Due to the complex nature of KS12 smooth surface parameterization, it was not computationally feasible to apply the Sobol' method. Instead, the OAT approach was applied for water and ice/snow surfaces. Note that the total number of input parameters that go into each model varies between parameterizations, and LUC types. For each parameterization, five particle sizes $\left(d_{\mathrm{p}}=0.001,0.01,0.1,1.0\right.$, and $10 \mu \mathrm{m})$ were assessed for Sobol' analysis. The sensitivity of each parameterization was tested for the following three sets of input parameters for five LUCs: (i) particle properties, (ii) aerodynamic parameters, and (iii) surface characteristics of particle deposition. First, the sensitivity of particle depo- sition to particle properties (aerodynamic diameter and density) was tested. Sensitivity indices were calculated for the particle size range of 0.001 to $10 \mu \mathrm{m}$. Second, the sensitivity of the schemes was tested for aerodynamic parameters (friction velocity, wind speed, and stability condition) for different particle sizes, one at a time. Third, the sensitivity of the schemes to surface characteristics was tested. Surface characteristics include $h, z_{0}, d$, and LAI. The sensitivity ranges for the parameter values used for Sobol' analysis are reported in Table 3.

The Sobol 2007 package in the R statistical software package (version 3.2.4) was used to perform the Sobol' sensitivity analysis. In the Sobol' method, the Monte Carlo simulations were performed by drawing samples from the assigned parameter value distribution. In this study, all the selected parameters were approximated using uniform PDFs. To assert uncertainty in the simulations, bootstrapping (Efron and Tibshirani, 1994) with resampling was used to achieve $95 \%$ confidence intervals on the Sobol' first-order indices. For a fixed particle size, the simulations were run 100000 times and samples were bootstrapped 1000 times. To identify the most important parameters in each of the five dry deposition models with respect to particle size and LUC, a parameter ranking (e.g., from most to least influential) was conducted.

The results section is organized in the following manner. First, the accuracy of five dry deposition parameterizations (i.e., Z01, PZ10, KS12, ZH14, and ZS14) is compared with measured dry deposition velocities obtained from five LUCs. Second, the uncertainties in modeled dry deposition velocities due to the imprecision in the model input parameter values quantified using Monte Carlo simulation techniques are presented. Third, the sensitivity analysis results for mod- 
Table 3. Input parameter ranges for the Sobol' sensitivity analysis.

\begin{tabular}{lll}
\hline Parameter & Range & Reference \\
\hline Relative humidity, RH $(\%)$ & $10-100$ (all LUCs) & Assumed \\
Dry particle density, $\rho\left(\mathrm{kg} \mathrm{m}^{-3}\right)$ & $1500-2000$ (all LUCs) & Studies 1-29 \\
Wind speed, $U\left(\mathrm{~m} \mathrm{~s}^{-1}\right)$ & $1-5$ (all LUCs) & Studies 1-29 \\
Friction velocity, $u_{*}\left(\mathrm{~m} \mathrm{~s}^{-1}\right)$ & $0.1-0.5$ (all LUCs) & Studies 1-29 \\
Monin-Obukhov length, $L_{\mathrm{O}}(\mathrm{m})$ & $10-100$ (all LUCs) & Studies 1-29 \\
Roughness length, $z_{0}(\mathrm{~m})$ & $0.02-0.10$ (grass) & Studies 1-5 \\
& $0.9-3.0$ (coniferous forest) & Studies 6-14 \\
& $0.5-1.5$ (deciduous forest) & Studies 15-17 \\
& $0.00002-0.0066$ (ice/snow) & Studies 22-29 \\
Canopy height, $h(\mathrm{~m})$ & $0.15-0.77$ (grass) & Studies 1-5 \\
& $14-20$ (coniferous forest) & Studies 6-14 \\
Zero-plane displacement height, $d(\mathrm{~m})$ & $20-25$ (deciduous forest) & Studies 15-17 \\
& $0.10-0.49$ (grass) & Studies 1-5 \\
& $7-12$ (coniferous forest) & Studies 6-14 \\
Leaf area index (one-sided), LAI $\left(\mathrm{m}^{2} \mathrm{~m}^{-2}\right)$ & $8-16$ (deciduous forest) & Studies 15-17 \\
& $0.2-10$ (grass) & Studies 1-5 \\
& $0.2-10$ (deciduous forest) & Studies 6-14 \\
& & Studies 15-17 \\
\hline
\end{tabular}

* Studies are listed in Table 1.

eled dry deposition velocities by the five parameterizations are presented.

\section{Results}

\subsection{Evaluation of the dry deposition parameterizations}

Field measurements conducted on five LUCs (grass, coniferous forest, deciduous forest, water surfaces, and ice/snow) were used to evaluate the agreement between measured and modeled dry deposition velocity $\left(V_{\mathrm{d}}\right)$. The parameterizations were run using reported values of the meteorological (e.g., $U, u_{*}, T, \mathrm{RH}$, and $L_{\mathrm{O}}$ ) and canopy (e.g., $h, z_{0}, d$, and LAI) parameters, and particle properties (e.g., $d_{\mathrm{p}}$ and $\rho$ ) from the measurement studies. Reasonable parameter values were assumed for any missing or unreported parameters. Normalized mean bias factors $\left(B_{\mathrm{NMBF}}\right)$ were used as an indicator of the agreement between measured and modeled $V_{\mathrm{d}} . B_{\mathrm{NMBF}}$ is a signed quantity - its magnitude indicates the factor by which the modeled and observed $V_{\mathrm{d}}$ values differ from each other, and its sign provides an indicator as to whether the modeled $V_{\mathrm{d}}$ is greater or less than the measured $V_{\mathrm{d}}$. It is to be noted that uncertainties in the measured dry deposition velocities were not considered while evaluating the performance of the five parameterizations in terms of accuracy.

\subsubsection{Evaluation of dry deposition to grass}

Five measurement studies conducted on grass (Wesely et al., 1977; Allen et al., 1991; Neumann and den Hartog, 1985; Nemitz et al., 2002; and Vong et al., 2004) were used to evaluate the accuracy of the parameterizations. In those studies, reported values of meteorological parameters, canopy properties, and particle size vary widely. For example, the $u_{*}$ varies from 0.05 to $0.70 \mathrm{~m} \mathrm{~s}^{-1}$, wind speed $(U)$ varies from 0.67 to $6.20 \mathrm{~m} \mathrm{~s}^{-1}$, particle size $\left(d_{\mathrm{p}}\right)$ varies from 0.05 to $2.28 \mu \mathrm{m}$, and LAI varies from 2 to $4 \mathrm{~m}^{2} \mathrm{~m}^{-2}$. The parameterizations were fed with reported values from each of the studies to reduce any uncertainty in the accuracy comparison; however, for any missing parameter value(s), the assumed input parameter values typically fell within the aforementioned ranges.

Table 4 summarizes the $B_{\mathrm{NMBF}}$ for modeled $V_{\mathrm{d}}$ computed against five measurement studies on grass. The $B_{\mathrm{NMBF}}$ is interpreted as follows: for example, if $B_{\mathrm{NMBF}}$ is positive, the parameterization overestimates the measured $V_{\mathrm{d}}$ by a factor of $B_{\mathrm{NMBF}}+1$. If $B_{\mathrm{NMBF}}$ is negative, the model underestimates the measured $V_{\mathrm{d}}$ by a factor of $1-B_{\mathrm{NMBF}}$. For the case using the observations from Allen et al. (1991), the $B_{\mathrm{NMBF}}$ values of $-17.61,-18.12,-0.55$, and -5.13 indicate that the Z01, KS12, ZH14, and ZS14 parameterizations underestimated the measured $V_{\mathrm{d}}$ by factors of $18.61,19.12,1.55$, and 6.13, respectively, whereas the $B_{\mathrm{NMBF}}$ value of +15.96 indicates that the PZ10 parameterization overestimated the observations by a factor of 16.96 .

These results provide means for a relative comparison of the parameterizations' accuracy. For instance, the $B_{\mathrm{NMBF}}$ values corresponding to the Allen et al. (1991) study suggest that the ZH14 parameterization is the most accurate and the KS12 parameterization is least accurate. Similar comparison between the modeled and observed $V_{\mathrm{d}}$ can be made using the $B_{\mathrm{NMBF}}$ values for the remaining four studies in Table 4 . 
Table 4. Results of the normalized mean bias factors for grass (boldfaced value indicates the most accurate parameterization).

\begin{tabular}{lrrrrr}
\hline & \multicolumn{5}{c}{ Dry particle deposition parameterization } \\
\cline { 2 - 6 } Study & Z01 & PZ10 & KS12 & ZH14 & ZS14 \\
\hline Allen et al. (1991) & -17.61 & 15.96 & -18.12 & -0.55 & -5.13 \\
Wesely et al. (1977) & -2.78 & -28.78 & -7.56 & -10.62 & -102.92 \\
Neumann and den Hartog (1985) & 0.96 & -0.12 & -0.50 & 4.79 & 0.56 \\
Nemitz et al. (2002) & 5.15 & 1.12 & -3.82 & 2.17 & -0.10 \\
Vong et al. (2004) & -4.55 & -4.55 & -25.71 & -2.12 & -4.03 \\
\hline Five studies & 5.45 & -1.80 & -9.37 & $\mathbf{- 0 . 5 4}$ & -4.30 \\
\hline
\end{tabular}

Nonetheless, it is evident that none of the parameterizations performed best in terms of accuracy for all of the five studies since the $B_{\mathrm{NMBF}}$ values show high variability both in terms of the magnitude and direction of the bias (i.e., positive or negative) when assessed against all the five studies listed in Table 4.

The characteristics of a parameterization (e.g., Z01) to simultaneously overpredict (i.e., the positive $B_{\mathrm{NMBF}}$ for Neumann and den Hartog, 1985, and Nemitz et al., 2002) and underpredict (i.e., the negative $B_{\mathrm{NMBF}}$ for Allen et al., 1991; Wesely et al., 1977; and Vong et al., 2004) the measurements could be misleading, resulting in erroneous judgement of the performance of the parameterizations. To address this limitation, an ensemble approach was taken, in which $B_{\mathrm{NMBF}}$ was calculated for each of the parameterizations using all the observations reported in the five studies. The results from this ensemble analysis indicate that, except for the Z01 parameterization, the other four parameterizations underestimated the measured $V_{\mathrm{d}}$ by factors ranging from 1.54 to 10.37 . In contrast, the Z01 parameterization overestimated the observation by a factor of 6.45 (Table 4). Overall, these results indicate that the $\mathrm{ZH} 14$ parameterization provided the best agreement between the measured and modeled $V_{\mathrm{d}}$ of the five parameterizations.

\subsubsection{Evaluation of dry deposition to coniferous forest}

Nine studies conducted on coniferous forest (Lamaud et al., 1994; Wyers and Duyzers, 1997; Gallagher et al., 1997; Ruijgrok et al., 1997; Rannik et al., 2000; Buzorious et al., 2000; Gaman et al., 2004; Pryor et al., 2007; and Grönholm et al., 2009) were used to evaluate the accuracy of the parameterizations. In these studies, the largest variations (ranges are given in the parentheses) were associated with $u_{*}(0.06-$ $\left.1.30 \mathrm{~m} \mathrm{~s}^{-1}\right), U\left(0.60-6.19 \mathrm{~m} \mathrm{~s}^{-1}\right)$, LAI $\left(6-10 \mathrm{~m}^{2} \mathrm{~m}^{-2}\right)$, and $d_{\mathrm{p}}(0.01-0.60 \mu \mathrm{m})$. For any missing parameter value(s), the assumed input parameter values typically fell within the aforementioned ranges.

Comparison of the computed $B_{\mathrm{NMBF}}$ values for coniferous forest (Table 5) shows that the majority of the simulations performed using the five parameterizations underestimated the measured $V_{\mathrm{d}}$. For example, the PZ10 parameterization underestimated observed $V_{\mathrm{d}}$ by factors ranging from 1.51 to 27.98 ( $B_{\mathrm{NMBF}}$ values varied from -0.51 to -26.98 ) for eight of the nine studies on coniferous forest. Table 5 also illustrates that both the magnitude and sign of the $B_{\mathrm{NMBF}}$ values varied widely when the accuracy of the five parameterizations was evaluated against only one study (e.g., Pryor et al., $2007)$. Of the $B_{\mathrm{NMBF}}$ values associated with the Rannik et al. (2000) study, the Z01 and KS12 parameterizations overestimated the measured $V_{\mathrm{d}}$ by factors of 4.16 and 1.51 , respectively, whereas the PZ10, ZH14, and ZS14 parameterizations underestimated the measured $V_{\mathrm{d}}$ by factors of $3.54,2.13$, and 19.75 , respectively. The bias factors for the Z01 parameterization for the studies of Lamaud et al. (1994), Gallagher et al. (1997), Buzorious et al. (2000), and Gaman et al. (2004) were $+0.77,-1.74,+0.75$, and -0.90 , respectively. Comparing these values with the corresponding $B_{\mathrm{NMBF}}$ values of the other four parameterizations, it can be deduced that the Z01 parameterization is the most accurate against those observations reported in these four studies. However, the accuracy of the Z01 parameterization is not the best for the other five studies, as can be seen from Table 5 .

An ensemble approach similar to the one described in the previous section was used to determine the most and the least accurate parameterizations. From this analysis, the bias factors for the Z01, PZ10, KS12, ZH14, and ZS14 parameterizations are $-2.35,-3.93,-1.75,-2.31$, and -3.67 , respectively, suggesting that the KS12 is the most accurate parameterization (i.e., underpredicted the observations by a factor of 2.75), and the PZ10 is the least accurate parameterization (i.e., underpredicted the observations by a factor of 4.93) for coniferous forest. It can be noted that the performance of the Z01 and ZH14 parameterizations is nearly identical, while the ZH14 is the second most accurate (i.e., underpredicted the observations by a factor of 3.31).

\subsubsection{Evaluation of dry deposition to deciduous forest}

A similar comparison between measured and modeled $V_{\mathrm{d}}$ was performed using three studies (Wesely et al., 1983; Pryor, 2006; and Matsuda et al., 2010) for deciduous forest. In these studies, the largest variations (ranges are given in the parentheses) were associated with $u_{*}\left(0.12-1.13 \mathrm{~m} \mathrm{~s}^{-1}\right)$, 
Table 5. Results of the normalized mean bias factors for coniferous forest (boldfaced value indicates the most accurate parameterization).

\begin{tabular}{lrrrrr}
\hline & \multicolumn{5}{c}{ Dry particle deposition parameterization } \\
\cline { 2 - 6 } Study & Z01 & PZ10 & KS12 & ZH14 & ZS14 \\
\hline Lamaud et al. (1994) & 0.77 & -12.75 & -1.91 & -2.14 & -16.71 \\
Wyers and Duyzers (1997) & -25.98 & -26.98 & -81.39 & -13.57 & -4.51 \\
Gallagher et al. (1997) & -1.74 & -6.34 & -19.83 & -1.90 & -2.39 \\
Ruijgrok et al. (1997) & -5.70 & -0.51 & -0.93 & -2.58 & -0.48 \\
Rannik et al. (2000) & 3.16 & -2.54 & 0.51 & -1.13 & -18.75 \\
Buzorious et al. (2000) & 0.75 & -6.65 & -2.91 & -4.53 & -67.41 \\
Gaman et al. (2004) & -0.90 & -13.00 & -6.12 & -1.84 & -17.45 \\
Pryor et al. (2007) & 0.69 & -5.37 & -0.26 & -0.84 & -12.22 \\
Grönholm et al. (2009) & 0.95 & 0.13 & 1.55 & 1.72 & -1.90 \\
\hline Nine studies & -2.35 & -3.93 & $\mathbf{- 1 . 7 5}$ & -2.31 & -3.67 \\
\hline
\end{tabular}

Table 6. Results of the normalized mean bias factors for deciduous forest (boldfaced values indicate the most accurate parameterization).

\begin{tabular}{lrrrrr}
\hline & \multicolumn{5}{c}{ Dry particle deposition parameterization } \\
\cline { 2 - 6 } Study & Z01 & PZ10 & KS12 & ZH14 & ZS14 \\
\hline Wesely et al. (1983) & -9.25 & -130.30 & -34.58 & -5.27 & -2.28 \\
Pryor (2006) & 1.55 & -2.42 & -2.42 & -0.90 & -13.62 \\
Matsuda et al. (2010) & -5.19 & -1.34 & -1.91 & -2.37 & -0.15 \\
\hline Three studies & -8.11 & -4.51 & -4.96 & $\mathbf{- 3 . 7 5}$ & -10.93 \\
\hline
\end{tabular}

$U\left(1.20-6.00 \mathrm{~m} \mathrm{~s}^{-1}\right)$, LAI $\left(0.20-10 \mathrm{~m}^{2} \mathrm{~m}^{-2}\right)$, and $d_{\mathrm{p}}(0.05-$ $2.50 \mu \mathrm{m})$. For any missing parameter value(s), the assumed input parameter values typically fell within the aforementioned ranges.

Computed $B_{\mathrm{NMBF}}$ values for deciduous forest are presented in Table 6. For the Wesely et al. (1983) study, comparison of the $B_{\mathrm{NMBF}}$ values between the parameterizations shows that the performance of the ZS14 parameterization was the most accurate (i.e., $B_{\mathrm{NMBF}}=-2.28$; underpredicted the observations by a factor of 3.28). The $B_{\mathrm{NMBF}}$ values associated with the PZ10 parameterization showed strong variation between the studies (e.g., 2 orders of magnitude discrepancy between the Wesely et al., 1983 and Pryor, 2006 or Matsuda et al., 2010 studies).

Evidently, none of the parameterizations performed consistently better for all the three studies. Overall, the results from the ensemble approach show that all the parameterizations overestimated the observations reported in three studies. Considering the $B_{\mathrm{NMBF}}$ values obtained by this approach, it is apparent that the $\mathrm{ZH} 14$ is the most accurate parameterization (i.e., $B_{\mathrm{NMBF}}=-3.75$; underestimated the observed $V_{\mathrm{d}}$ by a factor of 4.75 ), and the ZS14 is the least accurate of the five parameterizations (i.e., $B_{\mathrm{NMBF}}=-10.93$; underestimated the observed $V_{\mathrm{d}}$ by a factor of 11.93) for deciduous forest.

\subsubsection{Evaluation of dry deposition to water surfaces}

Only a limited number of measurement studies on sizesegregated dry deposition over natural water surfaces are available in the literature. In this research, four studies (Möller and Schumann, 1970, Sehmel et al., 1974, Zuffal et al., 1998, and Caffery et al., 1998) conducted over water surfaces were used to evaluate the parameterizations' accuracy. From these studies, the reported values of the parameters that show the largest variations (ranges are given in the parentheses) are $u_{*}\left(0.11-0.40 \mathrm{~m} \mathrm{~s}^{-1}\right)$ and $d_{\mathrm{p}}(0.03$ to $48 \mu \mathrm{m})$.

Table 7 shows that the PZ10 parameterization performed best for two studies (i.e., Möller and Schumann, 1970 and Caffery et al., 1998), in which $B_{\mathrm{NMBF}}$ values were -1.65 and +0.35 , respectively. Comparison of the $B_{\mathrm{NMBF}}$ values between the Z01 and ZH14 parameterizations reveals that the accuracy of the two parameterizations varied widely among the studies (e.g., $B_{\mathrm{NMBF}}$ ranged from -0.144 to +18.87 and -0.33 to +10.28 , respectively). Nevertheless, none of the five parameterizations was able to reproduce the measured $V_{\mathrm{d}}$ satisfactorily for all the four studies. Comparison of the $B_{\mathrm{NMBF}}$ values obtained by the ensemble approach showed that the ZH14 parameterization is the most accurate, which underestimated the measured $V_{\mathrm{d}}$ by a factor of 1.25 (i.e., $\left.B_{\mathrm{NMBF}}=-0.25\right)$, and the PZ10 is the least accurate parameterization (i.e., $B_{\mathrm{NMBF}}=-0.89$ ). 
Table 7. Results of the normalized mean bias factors for water surfaces (boldfaced value indicates the most accurate parameterization).

\begin{tabular}{lrrrrr}
\hline & \multicolumn{5}{c}{ Dry particle deposition parameterization } \\
\cline { 2 - 6 } Study & Z01 & PZ10 & KS12 & ZH14 & ZS14 \\
\hline Möller and Schumann (1970) & 18.87 & -1.65 & -2.51 & 10.28 & 106.00 \\
Sehmel et al. (1974) & 0.44 & 0.45 & -0.59 & 1.51 & 3.65 \\
Zufall et al. (1998) & -0.144 & -0.39 & -0.47 & -0.33 & 5.14 \\
Caffrey et al. (1998) & 0.75 & 0.35 & -0.85 & 0.70 & 3.61 \\
\hline Four studies & 0.52 & -0.89 & -0.64 & $\mathbf{- 0 . 2 5}$ & 4.22 \\
\hline
\end{tabular}

Table 8. Results of the normalized mean bias factors for ice/snow surfaces (boldfaced value indicates the most accurate parameterization).

\begin{tabular}{lrrrr}
\hline & \multicolumn{3}{c}{ Dry particle deposition parameterization } \\
\cline { 2 - 5 } Study & Z01 & PZ10 & KS12 & ZH14 \\
\hline Gronlund et al. (2002) & -1.22 & -271.73 & -105.92 & -2.58 \\
Contini et al. (2010) & 5.68 & -57.22 & -24.96 & 0.62 \\
Held et al. (2011a) & 2.96 & -38.66 & -15.58 & 0.67 \\
Held et al. (2011b) & 2.78 & -42.93 & -16.71 & 0.52 \\
Donateo and Contini (2014) & 1.62 & -35.26 & -12.57 & -0.32 \\
Ibrahim et al. (1983) & 4.14 & -6.72 & -7.72 & 3.98 \\
Duan et al. (1988) & 0.22 & -12.09 & -15.49 & 0.42 \\
Nilsson and Rannik (2001) & 1.69 & -37.78 & -13.46 & -0.74 \\
\hline Eight studies & 1.98 & -53.03 & -21.80 & $\mathbf{0 . 2 6}$ \\
\hline
\end{tabular}

\subsubsection{Evaluation of dry deposition to snow and ice surfaces}

Two studies over snow (Ibrahim et al., 1983; and Duan et al., 1988) and six studies over ice surfaces (Nilsson and Rannik, 2001; Gronlund et al., 2002; Contini et al., 2010; Held et al., 2011a, b; and Donateo and Contini, 2014) were used to evaluate the accuracy of the four parameterizations (Z01, PZ10, KS12, and ZH14) for smooth surfaces. The ZS14 parameterization was not included here because it does not allow prediction of deposition over ice/snow surfaces. The $B_{\mathrm{NMFB}}$ values for the parameterizations are presented in Table 8 .

Of the four parameterizations, agreement between the modeled and measured $V_{\mathrm{d}}$ is not satisfactory for the PZ10 and KS12 parameterizations because they significantly underestimated the measured $V_{\mathrm{d}}$ (e.g., the bias factors from ensemble approach are -53.03 and -21.80 , respectively). In contrast, the $\mathrm{Z} 01$ and $\mathrm{ZH} 14$ parameterizations predicted the measured $V_{\mathrm{d}}$ with reasonable accuracy (e.g., the bias factors from ensemble approach were +1.98 and +0.26 , respectively). Table 8 also shows that the $\mathrm{ZH} 14$ parameterization performed best for six of the eight measurements in which the $B_{\mathrm{NMBF}}$ varied between -0.74 to 3.98 . Overall, for the nine studies combined (i.e., ensemble measurements), the ZH14 parameterization is the most accurate (overestimated the measured $V_{\mathrm{d}}$ by a factor of 1.26), and the PZ10 is the least accurate parameterization (underestimated the measured $V_{\mathrm{d}}$ by a factor of 54.03).

To summarize, the results from the ensemble evaluation of the parameterizations are graphically shown in Fig. $2 a-b$ for the five LUCs. The horizontal dotted-dashed line in the plots indicates $100 \%$ agreement between modeled and measured $V_{\mathrm{d}}$, whereas any dispersion from this line either above (i.e., overestimation) or below (i.e., underestimation) indicates the degree of the model's accuracy.

\subsection{Uncertainty analysis results from the Monte Carlo simulations}

The overall uncertainty in the modeled $V_{\mathrm{d}}$ due to imprecision in the model inputs was assessed by performing a set of Monte Carlo simulations on the five dry deposition parameterizations. Uncertainties (in terms of imprecision) in the following model input parameters: $\mathrm{RH}, U, u_{*}, L_{\mathrm{O}}, h, z_{0}$, $d$, and LAI were approximated using uniform distributions. Note that not all of the five parameterizations require an identical number of input parameters. For example, Monte Carlo simulations performed on rough surfaces (i.e., grass, coniferous, and deciduous forests) for the Z01, PZ10, KS12, ZH14, and ZS14 parameterizations; imprecision in four (RH, $L, u_{*}$, and $\left.z_{0}\right)$, eight (RH, $L, u_{*}, U, z_{0}, h, d$, and LAI), four (RH, $u_{*}, U$, and LAI), four (RH, $L, u_{*}$, and $\left.z_{0}\right)$, and two (RH, $\left.u_{*}\right)$ input parameters, respectively, was assessed to evaluate the overall uncertainty in modeled dry deposition velocities. 

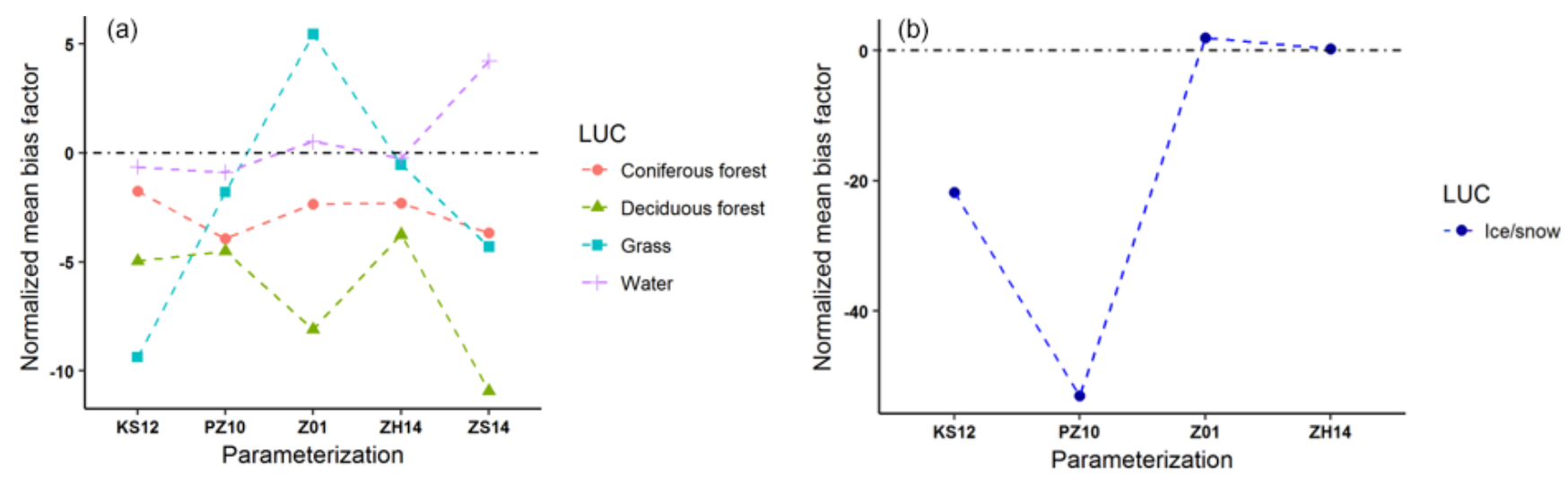

Figure 2. Ensemble-averaged, normalized mean bias factors for the five parameterizations: (a) three rough surfaces and water; (b) ice/snow.

The results from the Monte Carlo simulations are summarized in Table 9 and are presented and discussed in two steps. First, the uncertainty estimates that are shown in Table 9 for five parameterizations on five LUCs are used to elucidate the models' precision, which is one of the indicators of overall performance of the parameterization (Sect. 3.2.13.2.5). Second, the size-dependent uncertainty ranges (i.e., the difference between the 95 th and 5 th percentiles) was divided by the 50 th percentile $V_{\mathrm{d}}$, which can be treated as a normalized measure of uncertainty. This approach was taken to make reasonable comparison between different particle sizes for different parameterizations (Sect. 3.2.6). Note that the ZS14 parameterization does not treat different vegetative covers separately; therefore, intercomparison of the Monte Carlo simulation results is confined to the first four parameterizations listed in Table 9.

\subsubsection{Uncertainties in the modeled $V_{d}$ for grass}

The uncertainties in simulated $V_{\mathrm{d}}$ (i.e., differences between 95th and 5th percentiles of distribution) for the given range of $d_{\mathrm{p}}$ (i.e., $0.005-2.5 \mu \mathrm{m}$ ) on grass varied widely (Table 9). In the Z01 parameterization, the estimated uncertainty for nucleation mode particles $\left(0.0038 \mathrm{~m} \mathrm{~s}^{-1}\right.$ for $\left.d_{\mathrm{p}}=0.005 \mu \mathrm{m}\right)$ was larger than that of coarse mode particles $\left(0.0001 \mathrm{~m} \mathrm{~s}^{-1}\right.$ for $\left.d_{\mathrm{p}}>1.0 \mu \mathrm{m}\right)$. Overall, in the Z01 parameterization, the trend was that as the particle size increased from 0.005 to $2.5 \mu \mathrm{m}$, uncertainties in modeled $V_{\mathrm{d}}$ decreased considerably. In the PZ10 parameterization, the range of uncertainty for the simulated particle sizes is narrower compared to those of the Z01 parameterization. Although not consistent, a decreasing trend in uncertainties can be seen for all the particle sizes in the PZ10 parameterization. Of the simulated particle sizes, the uncertainty for $d_{\mathrm{p}}=0.005 \mu \mathrm{m}$ is the largest $\left(0.0016 \mathrm{~m} \mathrm{~s}^{-1}\right)$ in the $\mathrm{KS} 12$ parameterization. As particle size increased from 0.005 to $2.5 \mu \mathrm{m}$, significant decrease in uncertainties is observed. For $d_{\mathrm{p}}=0.05$ to $1.5 \mu \mathrm{m}$, the 5 th and 95th percentile $V_{\mathrm{d}}$ values were nearly identical (Table 9), suggesting that the KS12 parameterization is the most pre- cise of five parameterizations specifically for those particle sizes. From Table 9, it can be deduced that the uncertainties associated with the $\mathrm{ZH} 14$ parameterization, which is an improved and simplified version of the Z01 parameterization, were fairly constant (approximately $0.0003 \mathrm{~m} \mathrm{~s}^{-1}$ ) for the seven particle sizes simulated here for grass.

\subsubsection{Uncertainties in the modeled $V_{d}$ for coniferous forest}

For nucleation mode particles (i.e., $d_{\mathrm{p}}=0.005 \mu \mathrm{m}$ ), the largest uncertainty $\left(0.0036 \mathrm{~m} \mathrm{~s}^{-1}\right.$, median $V_{\mathrm{d}}=0.0180 \mathrm{~m} \mathrm{~s}^{-1}$ ) was associated with the Z01 parameterization (Table 9). Overall, the uncertainties in the Z01 parameterization showed a decreasing trend as the particle size increased from 0.005 to $2.5 \mu \mathrm{m}$. We note that, in the PZ10 parameterization, the relative magnitude of the uncertainties associated with $0.005,1.0,1.5,2.0$, and $2.5 \mu \mathrm{m}$ particles was of the same order (i.e., varied between 0.0010 to $\left.0.0031 \mathrm{~m} \mathrm{~s}^{-1}\right)$. In comparison, uncertainties in modeled $V_{\mathrm{d}}$ for 0.05 and $0.5 \mu \mathrm{m}$ particles were smaller by factors of approximately 10 . In the KS12 parameterization, the largest uncertainty was found for the nucleation mode particles (i.e., $0.0027 \mathrm{~m} \mathrm{~s}^{-1}$; median $V_{\mathrm{d}}=0.0299 \mathrm{~m} \mathrm{~s}^{-1}$ ), and the uncertainties in modeled $V_{\mathrm{d}}$ decreased substantially as $d_{\mathrm{p}}$ increased. The uncertainties in modeled $V_{\mathrm{d}}$ in the ZH14 parameterization were constant $\left(0.0002 \mathrm{~m} \mathrm{~s}^{-1}\right)$ for all seven particle sizes, indicating the model's ability to reproduce dry deposition velocities with high precision.

\subsubsection{Uncertainties in the modeled $V_{d}$ for deciduous forest}

A similar comparison of the uncertainties in modeled $V_{\mathrm{d}}$ can be made for deciduous forest. It is seen from Table 9 that, for all the parameterizations except for $\mathrm{ZH} 14$, the largest uncertainties were associated with nucleation mode particles. That is, Z01 and KS12 parameterizations showed substantially greater uncertainties for $d_{\mathrm{p}}=0.005 \mu \mathrm{m}(0.0030$ and 


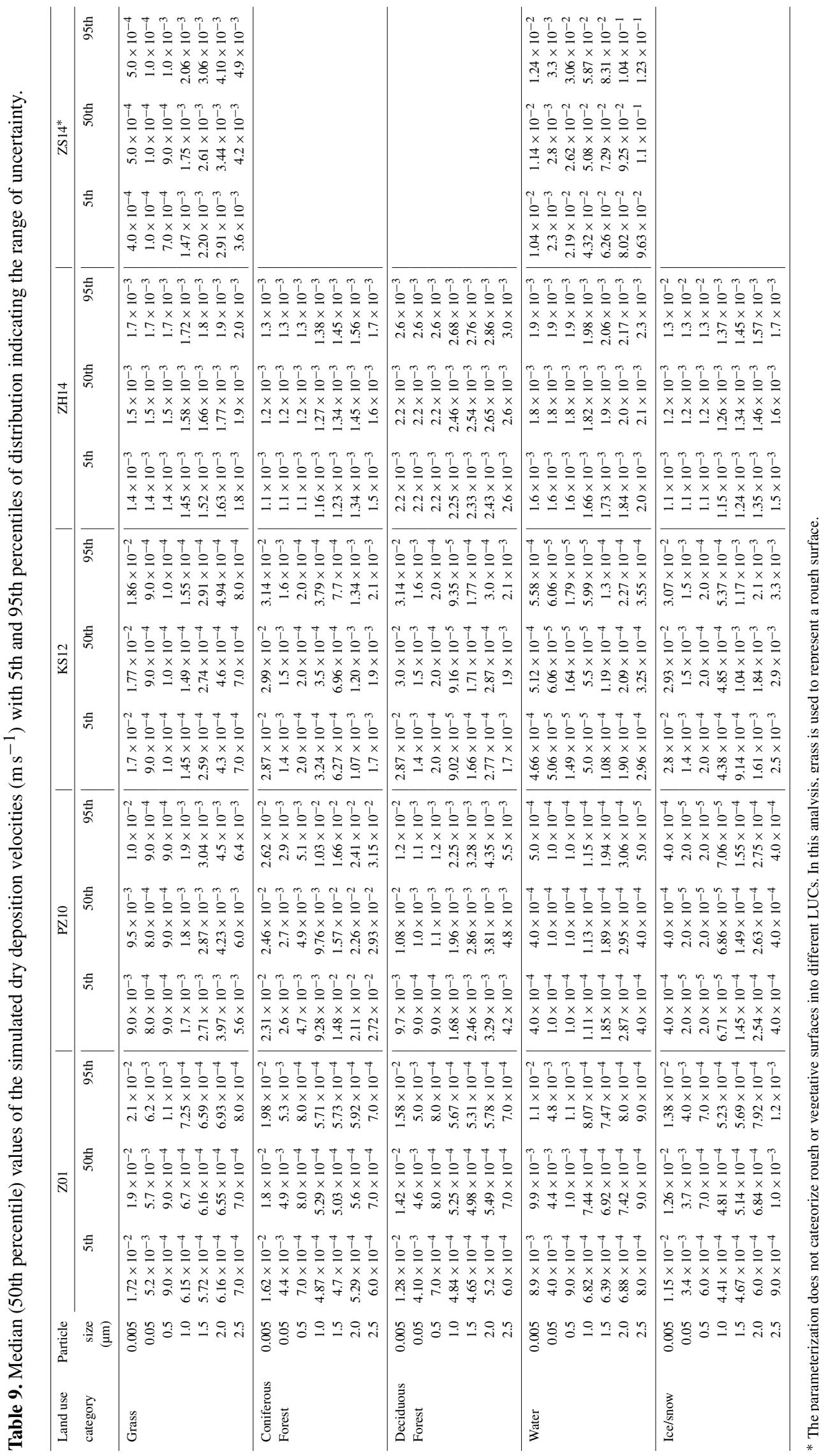


$0.0027 \mathrm{~m} \mathrm{~s}^{-1}$, respectively) as compared to the Aitken or coarse mode particles, for which the relative magnitude of the uncertainties was smaller by factors of approximately $13-$ 30. In the KS12 parameterization, the identical values of the 5th and 95 th percentile $V_{\mathrm{d}}$ values resulted in uncertainty values of zero for each simulated particle size of 0.5 to $2.0 \mu \mathrm{m}$, which indicates that it is the most precise of all four parameterizations. In addition, the uncertainties in the modeled $V_{\mathrm{d}}$ in the ZH14 parameterization were constant $\left(0.0004 \mathrm{~m} \mathrm{~s}^{-1}\right)$ for all seven particle sizes.

\subsubsection{Uncertainties in the modeled $V_{\mathrm{d}}$ for water surfaces}

For water surfaces, the uncertainties in modeled $V_{\mathrm{d}}$ varied largely for the Z01 parameterization (Table 9). That is, the largest uncertainty $\left(0.0021 \mathrm{~m} \mathrm{~s}^{-1}\right)$ was associated with $d_{\mathrm{p}}=0.005 \mu \mathrm{m}$ (median $V_{\mathrm{d}}=0.0099 \mathrm{~m} \mathrm{~s}^{-1}$ ), and as $d_{\mathrm{p}}$ increased to $2.5 \mu \mathrm{m}$, the uncertainty decreased to $0.0001 \mathrm{~m} \mathrm{~s}^{-1}$ (for $2.5 \mu \mathrm{m}$ particles, median $V_{\mathrm{d}}=0.0009 \mathrm{~m} \mathrm{~s}^{-1}$ ). Relatively narrower ranges in the uncertainties in modeled $V_{\mathrm{d}}$ for the PZ10 and KS12, and constant uncertainties in the ZH14 parameterizations with regard to changes in particle size suggest their higher precision as compared to the Z01 parameterization under similar model input parameter uncertainties. Overall, as compared to the simulated uncertainties in the modeled $V_{\mathrm{d}}$ by the Z01, PZ10, KS12, and ZH14 parameterizations, uncertainties in the ZS14 parameterization are larger for $d_{\mathrm{p}}=0.05$ to $2.5 \mu \mathrm{m}$.

\subsubsection{Uncertainties in the modeled $V_{d}$ for ice/snow surfaces}

Comparison between the simulated uncertainties in modeled $V_{\mathrm{d}}$ revealed that the uncertainties vary significantly for the $\mathrm{Z} 01$ and KS12 parameterizations as $d_{\mathrm{p}}$ changes. For example, uncertainties estimated from Table 9 for these two parameterizations decreased from 0.0023 to 0.0003 and 0.0027 to $0.0008 \mathrm{~m} \mathrm{~s}^{-1}$, respectively, as particle size increased from 0.005 to $2.5 \mu \mathrm{m}$. Note that the median $V_{\mathrm{d}}$ by the PZ10 parameterization is an order of magnitude lower than that of the other three parameterizations, which results in close to zero uncertainties for all seven particle sizes. It was also revealed in Table 9 that the uncertainties in the ZH14 parameterization are constant $\left(0.0002 \mathrm{~m} \mathrm{~s}^{-1}\right)$ with regard to changes in the particle size.

\subsubsection{Normalized uncertainties in the modeled $V_{\mathrm{d}}$}

An extended analysis of the results presented in the previous sections is summarized here. The normalized uncertainties presented in Table 10 can be interpreted as follows: any value that is closer to zero indicates higher model precision (i.e., less uncertainty). As shown in Table 10, the normalized uncertainties for grass and $d_{\mathrm{p}}=0.005 \mu \mathrm{m}$ associated with the Z01, PZ10, KS12, ZH14, and ZS14 parame-
Table 10. Normalized uncertainties in modeled dry deposition velocities.

\begin{tabular}{|c|c|c|c|c|c|c|}
\hline \multirow[b]{2}{*}{$\begin{array}{l}\text { Land use } \\
\text { category }\end{array}$} & \multirow[b]{2}{*}{$\begin{array}{r}\text { Particle size, } \\
d_{\mathrm{p}}(\mu \mathrm{m})\end{array}$} & \multicolumn{5}{|c|}{ Dry particle deposition parameterization } \\
\hline & & Z01 & PZ10 & KS12 & ZH14 & $\mathrm{ZS} 14$ \\
\hline \multirow[t]{7}{*}{ Grass } & 0.005 & 0.20 & 0.11 & 0.09 & 0.20 & 0.20 \\
\hline & 0.05 & 0.18 & 0.13 & 0.00 & 0.20 & 0.00 \\
\hline & 0.5 & 0.22 & 0.00 & 0.00 & 0.20 & 0.33 \\
\hline & 1.0 & 0.16 & 0.11 & 0.07 & 0.17 & 0.34 \\
\hline & 1.5 & 0.14 & 0.11 & 0.12 & 0.17 & 0.33 \\
\hline & 2.0 & 0.12 & 0.12 & 0.14 & 0.16 & 0.32 \\
\hline & 2.5 & 0.14 & 0.13 & 0.14 & 0.11 & 0.31 \\
\hline \multirow{7}{*}{$\begin{array}{l}\text { Coniferous } \\
\text { forest }\end{array}$} & 0.005 & 0.20 & 0.13 & 0.09 & 0.17 & \\
\hline & 0.05 & 0.18 & 0.11 & 0.13 & 0.17 & \\
\hline & 0.5 & 0.13 & 0.08 & 0.00 & 0.17 & \\
\hline & 1.0 & 0.16 & 0.10 & 0.16 & 0.17 & \\
\hline & 1.5 & 0.13 & 0.11 & 0.20 & 0.16 & \\
\hline & 2.0 & 0.11 & 0.13 & 0.22 & 0.15 & \\
\hline & 2.5 & 0.14 & 0.15 & 0.21 & 0.13 & \\
\hline \multirow{7}{*}{$\begin{array}{l}\text { Deciduous } \\
\text { forest }\end{array}$} & 0.005 & 0.21 & 0.21 & 0.09 & 0.18 & \\
\hline & 0.05 & 0.20 & 0.20 & 0.13 & 0.18 & \\
\hline & 0.5 & 0.13 & 0.27 & 0.00 & 0.18 & \\
\hline & 1.0 & 0.16 & 0.29 & 0.04 & 0.18 & \\
\hline & 1.5 & 0.13 & 0.28 & 0.06 & 0.17 & \\
\hline & 2.0 & 0.10 & 0.28 & 0.08 & 0.16 & \\
\hline & 2.5 & 0.14 & 0.27 & 0.21 & 0.15 & \\
\hline \multirow[t]{7}{*}{ Water } & 0.005 & 0.21 & 0.25 & 0.18 & 0.17 & 0.18 \\
\hline & 0.05 & 0.18 & 0.00 & 0.18 & 0.17 & 0.36 \\
\hline & 0.5 & 0.20 & 0.00 & 0.18 & 0.17 & 0.33 \\
\hline & 1.0 & 0.17 & 0.03 & 0.18 & 0.18 & 0.31 \\
\hline & 1.5 & 0.15 & 0.05 & 0.18 & 0.17 & 0.28 \\
\hline & 2.0 & 0.15 & 0.07 & 0.18 & 0.16 & 0.26 \\
\hline & 2.5 & 0.11 & 0.25 & 0.18 & 0.14 & 0.24 \\
\hline \multirow[t]{7}{*}{ Ice/snow } & 0.005 & 0.18 & 0.00 & 0.09 & 0.17 & \\
\hline & 0.05 & 0.16 & 0.00 & 0.07 & 0.17 & \\
\hline & 0.5 & 0.14 & 0.00 & 0.00 & 0.17 & \\
\hline & 1.0 & 0.17 & 0.05 & 0.20 & 0.17 & \\
\hline & 1.5 & 0.20 & 0.07 & 0.25 & 0.16 & \\
\hline & 2.0 & 0.28 & 0.08 & 0.27 & 0.15 & \\
\hline & 2.5 & 0.30 & 0.00 & 0.28 & 0.13 & \\
\hline
\end{tabular}

terizations are $0.20,0.11,0.09,0.20$, and 0.20 , respectively. These results suggest that KS12 is the least uncertain (i.e., most precise) parameterization for nucleation mode particles, whereas the Z01, ZH14, and ZS14 are the most uncertain (i.e., least precise) parameterizations. Similar comparisons can be made for other particle sizes, as well as between the different LUCs. For example, the uncertainties associated with $d_{\mathrm{p}}=0.05 \mu \mathrm{m}$ are greater for the PZ10 parameterization for deciduous forest as compared to grass $(0.20>0.13)$.

Comparison of the normalized uncertainties in modeled $V_{\mathrm{d}}$ over smooth surfaces (i.e., water and ice/snow) also reveals interesting findings. For example, for $d_{\mathrm{p}}=0.5 \mu \mathrm{m}$, the normalized uncertainties over water surfaces for the Z01, PZ10, KS12, and ZH14 parameterizations are 0.20, 0.00, 0.50 , and 0.17 , respectively. These results suggest that the PZ10 parameterization is the least uncertain (i.e., most pre- 

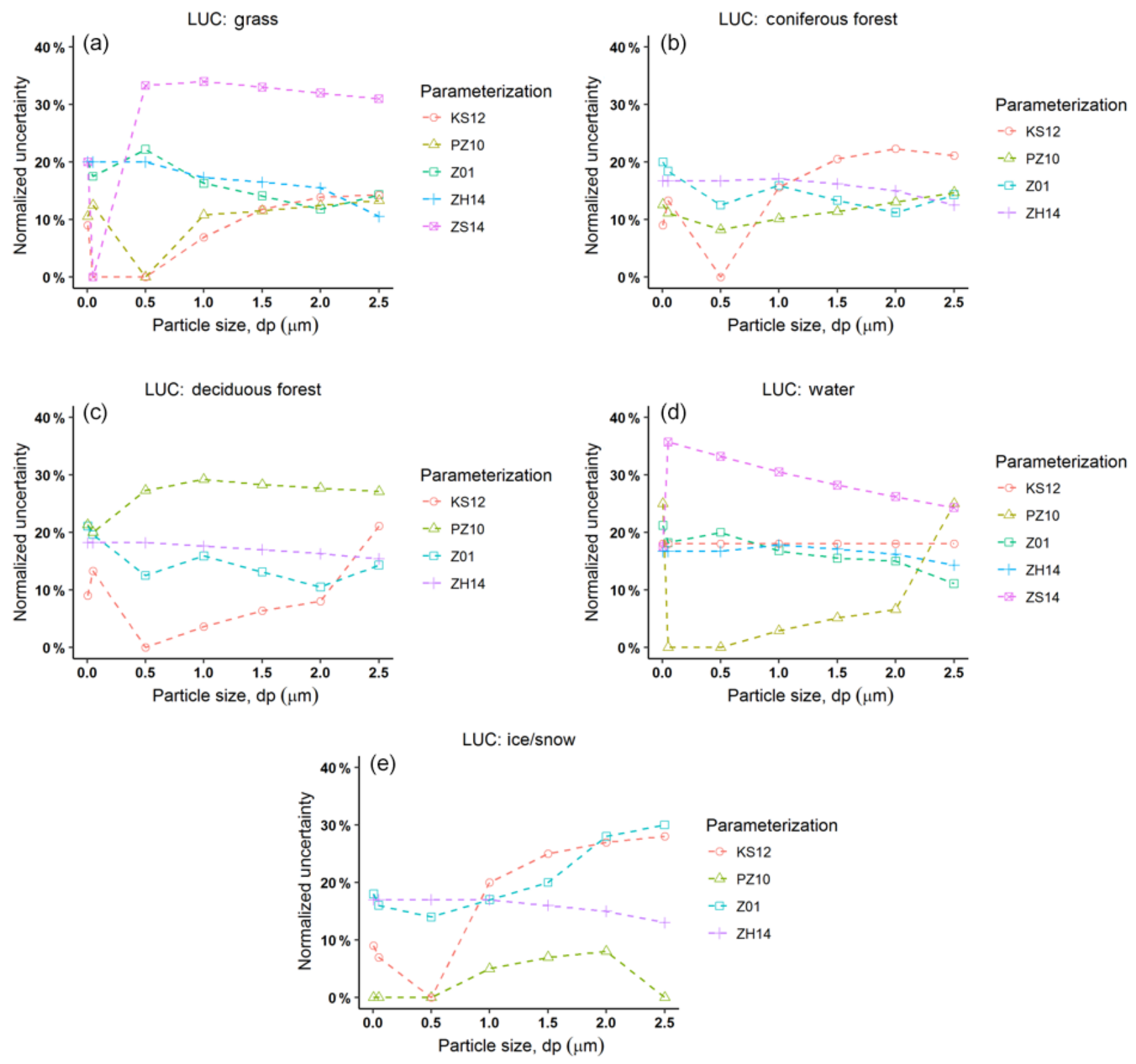

Figure 3. Comparison of the simulated uncertainties in the modeled dry deposition velocities as a function of particle size in five parameterizations for five LUCs.

cise), whereas the KS12 is the most uncertain (i.e., least precise) parameterization for accumulation mode particles. Over ice/snow surfaces, with $d_{\mathrm{p}}=0.005 \mu \mathrm{m}$, both the Z01 and ZH14 parameterizations have large uncertainties (normalized uncertainties are 0.18 and 0.17). In contrast, PZ10 is the most precise parameterization with close to zero normalized uncertainty value.

The normalized uncertainties presented in Table 10 also reveal interesting findings about the relative magnitude of imprecision for a given particle size on various LUCs by one parameterization. For example, with $d_{\mathrm{p}}=0.005 \mu \mathrm{m}$, the range in normalized uncertainties varies from 0.18 to 0.20 and 0.09 to 0.20 for all the five LUCs for the Z01 and KS12 parameterizations, respectively.

Figure $3 \mathrm{a}-\mathrm{e}$ show the relative comparison between uncertainties in modeled $V_{\mathrm{d}}$ by five parameterization for seven particle sizes across five LUCs. For LUC grass, Fig. 3a shows that the uncertainties in the Z01 and ZH14 parameterizations show nearly identical trends, which are relatively narrow. That is, the uncertainties for particle sizes from 0.005 to $2.5 \mu \mathrm{m}$ varied from 12 to 22 and 11 to $20 \%$ in the $\mathrm{Z} 01$ and ZH14 parameterizations, respectively. In contrast, uncertainties in the PZ10 and KS12 parameterizations exhibit large dispersion (i.e., uncertainty ranges from $\sim 0$ to $13 \%$ in the 
PZ10 and $\sim 0$ to $14 \%$ in the KS12 parameterizations). The largest uncertainties in the simulated $V_{\mathrm{d}}$ are associated with the ZS14 parameterization, in which the range of uncertainty varied from $\sim 0$ to $34 \%$ for the seven particle sizes. We note that the minimum $V_{\mathrm{d}}$ produced by the KS12 parameterization is at $d_{\mathrm{p}}=0.5 \mu \mathrm{m}$ for grass, coniferous and deciduous forest, and ice/snow surfaces, which can be confirmed from Fig. 3a-c and e. In addition, Fig. 3d-e show that the position of this minimum $V_{\mathrm{d}}$ in the PZ10 parameterization ranged from $d_{\mathrm{p}}=0.5$ to $1.0 \mu \mathrm{m}$ for water and ice/snow surfaces.

Similar comparison can be made to evaluate the relative magnitude of the uncertainties in the modeled $V_{\mathrm{d}}$ predicted by the parameterizations over other LUCs from Fig. 3b-e. In Fig. $3 \mathrm{~b}$, uncertainties in modeled $V_{\mathrm{d}}$ for coniferous forest ranged from 11 to 20,8 to $15, \sim 0$ to 21 , and 13 to $17 \%$ in the Z01, PZ10, KS12, and ZH14 parameterizations, respectively. In Fig. $3 c$, uncertainties in modeled $V_{\mathrm{d}}$ for deciduous forest ranged from 10 to 21,20 to $29, \sim 0$ to 21 , and 15 to $18 \%$ in the Z01, PZ10, KS12, and ZH14 parameterizations, respectively. In Fig. 3d, uncertainties in modeled $V_{\mathrm{d}}$ for water surfaces ranged from 11 to $21, \sim 0$ to $25,18,14$ to 18 , and 18 to $36 \%$ in the Z01, PZ10, KS12, ZH14, and ZS14 parameterizations, respectively. In Fig. 3e, uncertainties in modeled $V_{\mathrm{d}}$ for ice/snow surfaces ranged from 14 to $30, \sim 0$ to $8, \sim 0$ to 28 , and 13 to $17 \%$ in the Z01, PZ10, KS12, and ZH14 parameterizations, respectively.

\subsection{Sensitivity analysis results: Sobol' first-order sensitivity index}

For Sobol' first-order sensitivity analysis, five particle sizes (i.e., $d_{\mathrm{p}}=0.001,0.01,0.1,1.0$, and $10 \mu \mathrm{m}$ ) were selected. A sample size $(n)$ of 100000 was used for model evaluations for each of the five particle sizes. To assess the confidence intervals for the first-order Sobol' sensitivity index, bootstrapping resampling was used. In the bootstrapping method, the $n$ samples used for the sensitivity simulations were sampled 1000 times with replacement. In the following sections, the results from the Sobol' sensitivity analysis and evolution of the parameter rankings are presented.

The Sobol' sensitivity analysis performed here is used to achieve a ranking of the model input parameters. The ranking of the parameters from most to least sensitive of the five particle sizes for the five parameterizations is shown in Table 11. Tables S1-S5 in the Supplement show the first-order Sobol' indices of the various input parameters used in five dry deposition parameterizations for five LUCs. In these tables, the particle-size-dependent first-order Sobol' index $\left(S_{\mathrm{i}}\right)$ for different model input parameters is presented with $95 \%$ confidence intervals (CIs) obtained by bootstrap sampling. For example, the results of the first-order Sobol' indices for the Z01 parameterization on five LUCs are presented in Table S1. It is important to note that the number of parameters tested for Sobol' analysis varied between different LUCs, mainly because the number of parameters required for modeling $V_{\mathrm{d}}$ for one LUC may be greater or smaller compared to another LUC.

As shown in Table S1, for the Z01 parameterization on grass, the importance of the most influential parameters on the modeled dry deposition velocities for five particles sizes can be compared using the corresponding $S_{\mathrm{i}}$ values of the model input parameters $\left(i=\mathrm{RH}, \rho, L_{\mathrm{O}}, u_{*}\right.$, etc.). For example, with $d_{\mathrm{p}}=0.001 \mu \mathrm{m}$, it can be clearly seen that the $u_{*}$ is by far the single most sensitive parameter with an $S_{\mathrm{i}}$ value of 0.918 , which indicates that $91.8 \%$ of the variation in the modeled $V_{\mathrm{d}}$ can be attributed to variations in $u_{*}$. The other parameters that have significant effect on the modeled $V_{\mathrm{d}}$ are $z_{0}$ and $L_{\mathrm{O}}$. These two parameters have $S_{\mathrm{i}}$ values of 0.044 and 0.009 , respectively. As compared to the first-order Sobol' value of $u_{*}$, these values are significantly smaller; however, the lower limits of the corresponding $95 \%$ confidence intervals for $z_{0}$ and $L_{\mathrm{O}}$ are greater than zero, indicating that they have a significant effect on the modeled velocities. The $S_{\mathrm{i}}$ values for the other two parameters, $\mathrm{RH}$ and particle $\rho$, were approximately zero for $d_{\mathrm{p}}=0.001 \mu \mathrm{m}$ (Table $\mathrm{S} 1$ ) and indicate that these variables have no influence on the modeled $V_{\mathrm{d}}$.

Comparison between the first-order Sobol' indices for different particle sizes for grass shows strong variations for certain input parameters, which reveals interesting findings about the relative importance (from the most to the least) of the model input parameters to the modeled dry $V_{\mathrm{d}}$. For example, as seen from Table $\mathrm{S} 1$, as $d_{\mathrm{p}}$ increases from 0.001 to $10 \mu \mathrm{m}, S_{\mathrm{i}}$ values of $u_{*}$ decrease from 0.918 to 0.245 , which indicates that deposition of coarse particles is not strongly influenced by variations in friction velocity. From Table S1 it is also seen that parameters that influence particle properties (i.e., RH and $\rho_{\mathrm{P}}$ ) have higher $S_{\mathrm{i}}$ values for the coarse particles as compared to the fine or accumulation mode particles. Similar comparisons between size-dependent behavior of parameter sensitivity for other rough surfaces (i.e., coniferous and deciduous forests) can be made using the $S_{\mathrm{i}}$ values reported in Table S1.

The results of the first-order Sobol' indices for the Z01 parameterization on two smooth surfaces (water and ice/snow) are also presented in Table S1. Over liquid water surfaces, variation in $u_{*}$ values has the largest influence modeled $V_{\mathrm{d}}$ for $d_{\mathrm{p}}=0.001$ to $10.0 \mu \mathrm{m}$. As is seen from Table $\mathrm{S} 1$, the $S_{\mathrm{i}}$ values of $u_{*}$ can alone explain $98.3-99.5 \%$ of the variations in modeled $V_{\mathrm{d}}$ for particle sizes up to fine mode (i.e., $0.001-$ $0.01 \mu \mathrm{m})$. For coarse mode particles (e.g., $\left.d_{\mathrm{p}}=10 \mu \mathrm{m}\right), u_{*}$ is also the most influential parameter, contributing approximately $56 \%$ of the total variation in modeled $V_{\mathrm{d}}$, while relative humidity is the second most influential/sensitive parameter with an $S_{\mathrm{i}}$ value of 0.393 . The influence of $u_{*}$ also tends to dominate the modeled $V_{\mathrm{d}}$ over ice/snow surfaces. This theory can be confirmed by comparing the size-dependent $S_{\mathrm{i}}$ values of $u_{*}$ shown in Table $\mathrm{S} 1$, which suggest that $u_{*}$ is the single most sensitive parameter $\left(S_{\mathrm{i}}=0.978\right)$ for $d_{\mathrm{p}}=1.0 \mu \mathrm{m}$. As the particle size increased to $10 \mu \mathrm{m}, \mathrm{RH}$ and $u_{*}$ can ex- 
Table 11. Ranking of first-order Sobol' sensitivity indices for the five dry particle deposition parameterizations.

\begin{tabular}{|c|c|c|c|c|c|c|}
\hline $\begin{array}{l}\text { Land use } \\
\text { category }\end{array}$ & $d_{\mathrm{p}}(\mu \mathrm{m})$ & Z01 & PZ10 & KS12 & ZH14 & ZS14 \\
\hline \multirow[t]{5}{*}{ Grass } & 0.001 & $u_{*}, z_{0}, L_{\mathrm{O}},\left(\mathrm{RH}, \rho_{\mathrm{P}}\right)$ & $\begin{array}{l}u_{*}, \text { LAI, } z_{0}, U, L_{\mathrm{O}},(h, \\
\left.d, \mathrm{RH}, \rho_{\mathrm{P}}\right)\end{array}$ & $u_{*},\left(\mathrm{RH}, \rho_{\mathrm{P}}, \mathrm{LAI}\right)$ & $u_{*},\left(z_{0}, L_{\mathrm{O}}, \mathrm{RH}, \rho_{\mathrm{P}}\right)$ & $U, u_{*},\left(\mathrm{RH}, \rho_{\mathrm{P}}\right)$ \\
\hline & 0.01 & $u_{*}, z_{0}, L_{\mathrm{O}},\left(\mathrm{RH}, \rho_{\mathrm{P}}\right)$ & $\begin{array}{l}\text { LAI, } U, u_{*},\left(L_{\mathrm{O}}, h\right), \\
\left(z_{0}, d, \mathrm{RH}, \rho_{\mathrm{P}}\right)\end{array}$ & $u_{*},\left(\mathrm{RH}, \rho_{\mathrm{P}}, \mathrm{LAI}\right)$ & $u_{*},\left(z_{0}, L_{\mathrm{O}}, \mathrm{RH}, \rho_{\mathrm{P}}\right)$ & $U, u_{*},\left(\mathrm{RH}, \rho_{\mathrm{P}}\right)$ \\
\hline & 0.1 & $u_{*},\left(z_{0}, L_{\mathrm{O}}, \mathrm{RH}, \rho_{\mathrm{P}}\right)$ & $\begin{array}{l}\mathrm{AI}, U, d,\left(u_{*}, L_{\mathrm{O}}, h,\right. \\
\left.z_{0}, \mathrm{RH}, \rho \mathrm{P}\right)\end{array}$ & $u_{*},\left(\mathrm{RH}, \rho_{\mathrm{P}}, \mathrm{LAI}\right)$ & $u_{*},\left(z_{0}, L_{\mathrm{O}}, \mathrm{RH}, \rho_{\mathrm{P}}\right)$ & $u_{*}, U,\left(\mathrm{RH}, \rho_{\mathrm{P}}\right)$ \\
\hline & 1.0 & $u_{*}, \rho_{\mathrm{P}}, \mathrm{RH},\left(z_{0}, L_{\mathrm{O}}\right)$ & $\begin{array}{l}U, \mathrm{LAI}, \mathrm{RH}, u_{*}, L_{\mathrm{O}}, \\
\left(h, z_{0}, d, \rho_{\mathrm{P}}\right)\end{array}$ & $\mathrm{RH}, u_{*}, \rho_{\mathrm{P}}, \mathrm{LAI}$ & $u_{*},\left(z_{0}, L_{\mathrm{O}}, \mathrm{RH}, \rho_{\mathrm{P}}\right)$ & $u_{*}, U, \mathrm{RH}, \rho_{\mathrm{P}}$ \\
\hline & 10 & $\mathrm{RH}, u_{*}, \rho_{\mathrm{P}},\left(z_{0}, L_{\mathrm{O}}\right)$ & $\begin{array}{l}\mathrm{RH}, u_{*}, U, \mathrm{LAI},\left(\rho_{\mathrm{P}},\right. \\
\left.z_{0}\right), L_{\mathrm{O}},(h, d)\end{array}$ & $\mathrm{RH}, u_{*}, \mathrm{LAI}, \rho \mathrm{P}$ & $\mathrm{RH}, \rho_{\mathrm{P}},\left(u_{*}, L_{\mathrm{O}}, z_{0}\right)$ & $u_{*}, U, \mathrm{RH}, \rho \mathrm{P}$ \\
\hline \multirow[t]{5}{*}{$\begin{array}{l}\text { Coniferous } \\
\text { forest }\end{array}$} & 0.001 & $u_{*}, L_{\mathrm{O}}, z_{0},\left(\mathrm{RH}, \rho_{\mathrm{P}}\right)$ & $\begin{array}{l}u_{*}, L_{\mathrm{O}}, z_{0}, \mathrm{LAI}, h,(d, \\
\left.U, \mathrm{RH}, \rho_{\mathrm{P}}\right)\end{array}$ & $u_{*},\left(\mathrm{RH}, \rho_{\mathrm{P}}, \mathrm{LAI}\right)$ & $u_{*}, L_{\mathrm{O}},\left(z_{0}, \mathrm{RH}, \rho_{\mathrm{P}}\right)$ & \\
\hline & 0.01 & $u_{*}, L_{\mathrm{O}}, z_{0},\left(\mathrm{RH}, \rho_{\mathrm{P}}\right)$ & $\begin{array}{l}L_{\mathrm{O}}, \mathrm{LAI}, u_{*}, U, z_{0}, h, \\
\left(d, \mathrm{RH}, \rho_{\mathrm{P}}\right)\end{array}$ & $u_{*},\left(\mathrm{RH}, \rho_{\mathrm{P}}, \mathrm{LAI}\right)$ & $u_{*}, L_{\mathrm{O}},\left(z_{0}, \mathrm{RH}, \rho_{\mathrm{P}}\right)$ & \\
\hline & 0.1 & $u_{*}, L_{\mathrm{O}},\left(z_{0}, \mathrm{RH}, \rho \mathrm{P}\right)$ & $\begin{array}{l}L_{\mathrm{O}}, \mathrm{LAI}, U, u_{*},\left(d, z_{0},\right. \\
\left.h, \mathrm{RH}, \rho_{\mathrm{P}}\right)\end{array}$ & $u_{*},\left(\mathrm{RH}, \rho_{\mathrm{P}}, \mathrm{LAI}\right)$ & $u_{*},\left(L_{\mathrm{O}}, z_{0}, \mathrm{RH}, \rho_{\mathrm{P}}\right)$ & \\
\hline & 1.0 & $u_{*}, \rho \mathrm{P}, \mathrm{RH},\left(L_{\mathrm{O}}, z_{0}\right)$ & $\begin{array}{l}L_{\mathrm{O}}, U, \mathrm{LAI}, u_{*}, \mathrm{RH}, \\
\left(\rho_{\mathrm{P}}, d, z_{0}, h\right)\end{array}$ & $u_{*}, \mathrm{RH}, \rho \mathrm{P}, \mathrm{LAI}$ & $u_{*}, L_{\mathrm{O}},\left(z_{0}, \mathrm{RH}, \rho \mathrm{P}\right)$ & \\
\hline & 10 & $\mathrm{RH}, u_{*}, \rho_{\mathrm{P}}, L_{\mathrm{O}}, z_{0}$ & $\begin{array}{l}u_{*}, L_{\mathrm{O}}, \mathrm{RH}, z_{0},\left(\rho_{\mathrm{P}},\right. \\
U),(\mathrm{LAI}, d, h)\end{array}$ & $\mathrm{RH}, u_{*}, \mathrm{LAI}, \rho_{\mathrm{P}}$ & $\mathrm{RH}, u_{*}, L_{\mathrm{O}}, z_{0}, \rho_{\mathrm{P}}$ & \\
\hline \multirow[t]{5}{*}{$\begin{array}{l}\text { Deciduous } \\
\text { forest }\end{array}$} & 0.001 & $u_{*}, z_{0}, L_{\mathrm{O}},\left(\mathrm{RH}, \rho_{\mathrm{P}}\right)$ & $\begin{array}{l}L_{\mathrm{O}}, u_{*}, \mathrm{LAI}, z_{0}, U,(h, \\
\left.d, \mathrm{RH}, \rho_{\mathrm{P}}\right)\end{array}$ & $u_{*},\left(\mathrm{RH}, \rho_{\mathrm{P}}, \mathrm{LAI}\right)$ & $u_{*}, L_{\mathrm{O}},\left(z_{0}, \mathrm{RH}, \rho_{\mathrm{P}}\right)$ & \\
\hline & 0.01 & $u_{*}, z_{0}, L_{\mathrm{O}},\left(\mathrm{RH}, \rho_{\mathrm{P}}\right)$ & $\begin{array}{l}L_{\mathrm{O}}, \mathrm{LAI}, u_{*}, U,\left(z_{0},\right. \\
d),\left(h, \mathrm{RH}, \rho_{\mathrm{P}}\right)\end{array}$ & $u_{*},\left(\mathrm{RH}, \rho_{\mathrm{P}}, \mathrm{LAI}\right)$ & $u_{*}, L_{\mathrm{O}},\left(z_{0}, \mathrm{RH}, \rho_{\mathrm{P}}\right)$ & \\
\hline & 0.1 & $u_{*}, z_{0},\left(L_{\mathrm{O}}, \mathrm{RH}, \rho_{\mathrm{P}}\right)$ & $\begin{array}{l}L_{\mathrm{O}}, \mathrm{LAI}, U, u_{*}, d,\left(z_{0},\right. \\
\left.h, \mathrm{RH}, \rho_{\mathrm{P}}\right)\end{array}$ & $u_{*},\left(\mathrm{RH}, \rho_{\mathrm{P}}, \mathrm{LAI}\right)$ & $u_{*}, L_{\mathrm{O}},\left(z_{0}, \mathrm{RH}, \rho_{\mathrm{P}}\right)$ & \\
\hline & 1.0 & $u_{*}, \rho_{\mathrm{P}},\left(L_{\mathrm{O}}, z_{0}, \mathrm{RH}\right)$ & $\begin{array}{l}L_{\mathrm{O}}, \mathrm{LAI}, U, u_{*}, \mathrm{RH}, \\
\left(z_{0}, d\right),\left(h, \rho_{\mathrm{P}}\right)\end{array}$ & $\mathrm{RH}, \rho_{\mathrm{P}}, u_{*}, \mathrm{LAI}$ & $u_{*}, L_{\mathrm{O}},\left(z_{0}, \mathrm{RH}, \rho_{\mathrm{P}}\right)$ & \\
\hline & 10 & $\mathrm{RH}, u_{*}, \rho_{\mathrm{P}}, z_{0}, L_{\mathrm{O}}$ & $\begin{array}{l}L_{\mathrm{O}}, \mathrm{RH}, u_{*}, \mathrm{LAI}, \rho_{\mathrm{P}}, \\
U, z_{0},(d, h)\end{array}$ & $\mathrm{RH}, \rho_{\mathrm{P}}, u_{*}, \mathrm{LAI}$ & $\mathrm{RH}, u_{*}, \mathrm{LAI}, L_{\mathrm{O}}, \rho_{\mathrm{P}}, z_{0}$ & \\
\hline \multirow[t]{5}{*}{ Water } & 0.001 & $u_{*},\left(L_{\mathrm{O}}, \mathrm{RH}, \rho_{\mathrm{P}}\right)$ & $u_{*},\left(L_{\mathrm{O}}, \mathrm{RH}, \rho_{\mathrm{P}}\right)$ & $u_{*}, L_{\mathrm{O}},\left(\rho_{\mathrm{P}}, \mathrm{RH}\right)$ & $u_{*},\left(L_{\mathrm{O}}, \mathrm{RH}, \rho_{\mathrm{P}}\right)$ & \\
\hline & 0.01 & $u_{*},\left(L_{\mathrm{O}}, \mathrm{RH}, \rho_{\mathrm{P}}\right)$ & $u_{*},\left(L_{\mathrm{O}}, \mathrm{RH}, \rho_{\mathrm{P}}\right)$ & $u_{*}, L_{\mathrm{O}},\left(\rho_{\mathrm{P}}, \mathrm{RH}\right)$ & $u_{*},\left(L_{\mathrm{O}}, \mathrm{RH}, \rho_{\mathrm{P}}\right)$ & \\
\hline & 0.1 & $u_{*},\left(L_{\mathrm{O}}, \mathrm{RH}, \rho_{\mathrm{P}}\right)$ & $u_{*}, \rho_{\mathrm{P}},\left(L_{\mathrm{O}}, \mathrm{RH}\right)$ & $u_{*}, L_{\mathrm{O}},\left(\rho_{\mathrm{P}}, \mathrm{RH}\right)$ & $u_{*},\left(L_{\mathrm{O}}, \mathrm{RH}, \rho_{\mathrm{P}}\right)$ & \\
\hline & 1.0 & $u_{*}, \rho_{\mathrm{P}},\left(\mathrm{RH}, L_{\mathrm{O}}\right)$ & $\mathrm{RH}, \rho_{\mathrm{P}},\left(u_{*}, L_{\mathrm{O}}\right)$ & $\rho_{\mathrm{P}}, u_{*},(\mathrm{RH}, L)$ & $u_{*},\left(L_{\mathrm{O}}, \mathrm{RH}, \rho_{\mathrm{P}}\right)$ & \\
\hline & 10 & $u_{*}, \mathrm{RH},\left(\rho_{\mathrm{P}}, L_{\mathrm{O}}\right)$ & $\mathrm{RH}, \rho \mathrm{P},\left(u_{*}, L_{\mathrm{O}}\right)$ & $\rho_{\mathrm{P}}, u_{*}, L_{\mathrm{O}}, \mathrm{RH}$ & $u_{*}, \mathrm{RH},\left(L_{\mathrm{O}}, \rho_{\mathrm{P}}\right)$ & \\
\hline \multirow[t]{5}{*}{ Ice/snow } & 0.001 & $u_{*}, L_{\mathrm{O}},\left(z_{0}, \mathrm{RH}, \rho_{\mathrm{P}}\right)$ & $u_{*},\left(L_{\mathrm{O}}, z_{0}, \mathrm{RH}, \rho \mathrm{P}\right)$ & $u_{*}, \mathrm{RH}, \rho \mathrm{P}$ & $u_{*},\left(L_{\mathrm{O}}, z_{0}, \mathrm{RH}, \rho_{\mathrm{P}}\right)$ & \\
\hline & 0.01 & $u_{*}, z_{0}, L_{\mathrm{O}},\left(\mathrm{RH}, \rho_{\mathrm{P}}\right)$ & $u_{*},\left(L_{\mathrm{O}}, z_{0}, \mathrm{RH}, \rho_{\mathrm{P}}\right)$ & $u_{*}, \mathrm{RH}, \rho_{\mathrm{P}}$ & $u_{*},\left(L_{\mathrm{O}}, z_{0}, \mathrm{RH}, \rho_{\mathrm{P}}\right)$ & \\
\hline & 0.1 & $u_{*},\left(L_{\mathrm{O}}, z_{0}, \mathrm{RH}, \rho_{\mathrm{P}}\right)$ & $u_{*},\left(L_{\mathrm{O}}, z_{0}, \mathrm{RH}, \rho_{\mathrm{P}}\right)$ & $u_{*}, \mathrm{RH}, \rho_{\mathrm{P}}$ & $u_{*},\left(L_{\mathrm{O}}, z_{0}, \mathrm{RH}, \rho_{\mathrm{P}}\right)$ & \\
\hline & 1.0 & $u_{*},\left(L_{\mathrm{O}}, z_{0}, \mathrm{RH}, \rho_{\mathrm{P}}\right)$ & $\mathrm{RH}, \rho_{\mathrm{P}},\left(z_{0}, L_{\mathrm{O}}, z_{0}\right)$ & $u_{*}, \mathrm{RH}, \rho_{\mathrm{P}}$ & $u_{*},\left(L_{\mathrm{O}}, z_{0}, \mathrm{RH}, \rho_{\mathrm{P}}\right)$ & \\
\hline & 10 & $u_{*}, \mathrm{RH},\left(\rho_{\mathrm{P}}, L_{\mathrm{O}}, z_{0}\right)$ & $\mathrm{RH}, \rho_{\mathrm{P}},\left(z_{0}, L_{\mathrm{O}}, z_{0}\right)$ & $\mathrm{RH}, u_{*}, \rho_{\mathrm{P}}$ & $u_{*}, \mathrm{RH},\left(z_{0}, L_{\mathrm{O}}, \rho_{\mathrm{P}}\right)$ & \\
\hline
\end{tabular}

Note that the ranking of the parameters is from most sensitive to least sensitive. Parameters within the parentheses have identical Sobol' first-order indices.

plain $92.7 \%$ of the total variation in modeled $V_{\mathrm{d}}$ in the $\mathrm{Z} 01$ parameterization.

The results of the first-order Sobol' indices for the PZ10 parameterization on five LUCs are presented in Table S2. The size-dependent $S_{\mathrm{i}}$ values on coniferous forest can be compared here to elucidate the contribution of different input parameters on the modeled $V_{\mathrm{d}}$. It can be noted that, on rough surfaces, the PZ10 parameterization was tested for the greatest number of input parameters (i.e., nine) among the five parameterizations. Some canopy properties such as $h, d$, and LAI, and meteorological properties such as $U$ were tested for their influence on modeled $V_{\mathrm{d}}$ in addition to those parameters that were tested for the rough surfaces in the Z01 parameterization. As seen from Table S2, for coniferous forest, for $d_{\mathrm{p}}=0.001 \mu \mathrm{m}, u_{*}$ and $L_{\mathrm{O}}$ are the two most influential parameters ( $S_{\mathrm{i}}$ values of 0.492 and 0.462 , respectively). Although LAI is not the most influential parameter for the range of $d_{\mathrm{p}}$ tested here, its influence on the overall variability in the modeled $V_{\mathrm{d}}$ increases from 0.5 to $31.3 \%$ as particle size increases from 0.001 to $0.1 \mu \mathrm{m}$. Similarly, wind speed tends to show an increasing influence as $d_{\mathrm{p}}$ increases from 0.001 to $1.0 \mu \mathrm{m}$ (overall contribution of $U$ in the variability 
in $V_{\mathrm{d}}$ shows an increase from 0.1 to $27.7 \%$ ). For coarse particles (i.e., $\left.d_{\mathrm{p}}=10 \mu \mathrm{m}\right), u_{*}$ and $L_{\mathrm{O}}$ are the two most influential parameters with $S_{\mathrm{i}}$ values of 0.372 and 0.350 , respectively. Together with $\mathrm{RH}$, the three parameters can explain $92 \%$ of the variation in the modeled $V_{\mathrm{d}}$. Results from the first-order Sobol' indices for the other LUCs for the PZ10 parameterization presented in Table S2 can be explained in a manner similar to that used to explain the contribution of the most sensitive parameters to the modeled dry deposition velocities. For the water surface, $u_{*}$ is the most influential parameter for $d_{\mathrm{p}}=0.001 \mu \mathrm{m}$ as $99.4 \%$ of the total variance on the modeled $V_{\mathrm{d}}$ is attributed to its variability. Indeed, for particle sizes up to $0.1 \mu \mathrm{m}$, the $u_{*}$ itself is most sensitive parameter. As seen from Table 11, RH becomes the most influential model parameter for $d_{\mathrm{p}}=1.0$ and $10.0 \mu \mathrm{m}$, which alone contribute to 69.5 and $95.6 \%$ of the total variabilities in the modeled $V_{\mathrm{d}}$, respectively.

Table S3 shows the first-order Sobol' indices for the KS12 parameterization on five LUCs. For brevity, the results of the first-order sensitivity indices for deciduous forest are discussed herein. It is seen that $u_{*}$ is the single most influential parameter for $d_{\mathrm{p}}=0.001$ to $0.1 \mu \mathrm{m}$ (e.g., total contribution on the modeled $V_{\mathrm{d}}$ attributable to $u_{*}$ ranges from 94.4 to $96.7 \%)$. For $d_{\mathrm{p}}=1.0$ and $10 \mu \mathrm{m}, \mathrm{RH}$ is the most influential parameter with $S_{\mathrm{i}}$ values of 0.629 and 0.934 , respectively.

Table S4 shows the first-order Sobol' indices for the ZH14 parameterization on five LUCs. The results show a strong influence of $u_{*}$ on the modeled $V_{\mathrm{d}}$. As shown in Table S4, the $S_{\mathrm{i}}$ values alone can explain nearly $100 \%$ of the variation in the modeled $V_{\mathrm{d}}$ for $d_{\mathrm{p}}=0.001$ to $1.0 \mu \mathrm{m}$. For large particles (e.g., $\left.d_{\mathrm{p}}=10 \mu \mathrm{m}\right), \mathrm{RH}$ is the most influential parameter; however, the contributions of other parameters as listed in Table S4 vary with regard to changes in LUCs.

\section{Discussion}

The accuracy of the parameterizations should be interpreted within the context of the field measurements used in this study assuming that they were accurate. In addition, the intercomparison of the parameterizations' accuracy is subject to uncertainties with regard to the assumed values of missing meteorological parameters, particle properties, or surface features. Evidently, the normalized mean bias factors obtained using the ensemble approach are a useful measure to intercompare the parameterizations' performance against a subset of field measurements for a given LUC. Extending the comparison of the normalized mean bias factors across the five LUCs for the five parameterizations investigated in this study provides a relative assessment of their accuracy. However, the ZH14 parameterization is most accurate for all parameterizations except coniferous forest, where it is a close second to the KS12 parameterization.

For rough surfaces, our results suggest that ZH14 is the most accurate parameterization for grass and deciduous for- est, and it is the second most accurate parameterization for coniferous forest. In contrast, KS12, PZ10, and ZS14 are the least accurate parameterizations for grass, coniferous, and deciduous forests, respectively. It is interesting that in most cases the models underpredicted the measured dry deposition velocities (negative bias factors in Tables 4-8). Indeed, for grass, except for the Z01 parameterization, the other four parameterizations underpredicted the measured $V_{\mathrm{d}}$ by factors of 1.54 to 10.37 ( $B_{\mathrm{NMBF}}$ varied from -0.54 to -9.37 ). With regard to deciduous and coniferous forests, all of the five models (from the most to the least accurate: ZH14, PZ10, KS12, Z01, and ZS14; KS12, ZH14, Z01, ZS14, and PZ10) underpredicted the measured $V_{\mathrm{d}}$ by factors of 4.75 to 11.93 , and 2.75 to 4.93 , respectively.

A direct quantitative comparison of the accuracy of the five parameterizations with those reported in other studies is impossible because the metric used in the present study $\left(B_{\mathrm{NMBF}}\right)$ is not commonly used to evaluate the accuracy of the dry deposition models. However, qualitatively, our findings regarding the PZ10 performance for coniferous forests are in accordance with those reported by Petroff and Zhang (2010). They reported that the PZ10 parameterization underpredicted the measured deposition velocities for the subset of observations that we also investigated for coniferous forest - Lamaud et al. (1994), Gallagher et al. (1997), Buzorious et al. (2000), Gaman et al. (2004) - and overpredicted for Grönholm et al. (2009).

The accuracy results over smooth surfaces suggest that, for the water surface, the best agreement between the measured and modeled $V_{\mathrm{d}}$ was found for the $\mathrm{ZH} 14$ parameterization. Overall, the accuracy ranking from best to worst is as follows: ZH14, Z01, KS12, PZ10, and ZS14. Over ice/snow surface, the results suggest that the ZH14 is the most accurate parameterization, and PZ10 is the least accurate. Qualitatively, this finding is consistent with Petroff and Zhang (2010), who reported that their model significantly underestimated the measured deposition velocities over ice/snow surface for the following studies: Ibrahim et al. (1983), Duan et al. (1988), Nilsson and Rannik (2001), and Contini et al. (2010), which were also investigated in the present study. We also note that the Z01 parameterization overestimated the measured $V_{\mathrm{d}}$ from the aforementioned studies. This finding is consistent with Petroff and Zhang (2010), as they compared their model with Z01 over the ice/snow surface. One possible explanation for a large discrepancy between modeled and measured $V_{\mathrm{d}}$ by PZ10 is an incorrect magnitude of the drift velocity applied, corresponding to phoretic effects on ice and snow.

Collectively for both rough and smooth surfaces, it is found that the $\mathrm{ZH} 14$ scheme is the most accurate for these LUCs: grass, deciduous forest, water, and ice/snow surfaces. KS12 performed slightly better for coniferous forest only. The performance of the PZ10 scheme could be viewed as moderate. This finding is interesting considering that the $\mathrm{ZH} 14$ is the simplest resistance-based scheme of the five pa- 
rameterizations. We emphasize that Z01 and ZH14 parameterizations share similar structural features, but simplifications of the particle collection processes by constant values by ZH14 (see Eqs. 46-50) could produce better agreement. In addition, we note that the KS12 parameterization is based exclusively on wind tunnel measurements and its performance over forest canopies is not satisfactory, as reported by the model developers Kouznetsov and Sofiev (2012). However, we find that KS12 performed the best over coniferous forests with the nine studies used in this research. However, Kouznetsov and Sofiev (2012) did not use the same subset of studies to evaluate the model performance as we used.

Given the complex nature and incomplete knowledge of the dry deposition process, it is important to account for the uncertainties in the modeled deposition velocities in atmospheric transport models (Petroff and Zhang, 2010; Zhang et al., 2012). Although there have been many dry deposition models developed over the years, the information on the model output uncertainties is meager and not up to date. To assert uncertainty on the modeled dry deposition velocities, Gould and Davidson (1992) adopted a stepwise uncertainty test of Slinn's (1982) model. However, in reality, the model parameters are subject to simultaneous variability, and a OAT test cannot adequately propagate the error to the overall model outputs. This limitation was partially overcome by Ruijgrok (1992), who performed a probabilistic uncertainty test of Slinn's model.

The Monte Carlo uncertainty analysis performed in this study assumes that in the five parameterizations all the major physical processes (e.g., turbulent diffusion, Brownian diffusion, impaction, interception, and gravitational settling) of dry deposition are accounted for satisfactorily. Thus, the uncertainty analysis conforms to the uncertainties in the model input variables and their overall contribution to the propagated uncertainties in the modeled dry deposition velocities. Additional uncertainties in the modeled deposition velocities may arise from inadequate model formulation and/or inappropriate use of certain micrometeorological parameters. For example, in dry deposition models (such as PZ10), $d$ and $z_{0}$ are often calculated as a fraction of $h$ and are often taken as $d \approx 2 h / 3$ and $z_{0} \approx 0.1 h$. These expressions are valid for dense canopies (Katul et al., 2010). If the leaf area density is highly skewed or shows a bimodal distribution, such approximations cannot be used (Katul et al., 2010). In addition, the parameter values of $d$ and $z_{0}$ are subject to large uncertainty and are very difficult to measure in urban areas (Cherin et al., 2015). Therefore, caution must be taken when using constant $d$ and $z_{0}$ values from lookup tables. Also, current deposition models do not consider terrain complexity in their formulations. Hicks (2008) argued that conventional use of $d$ and $z_{0}$ for non-flat terrain such as mountains is not appropriate for modeling deposition on complex terrain. In addition, experimentally derived values of $d$ and $z_{0}$ often represent local characteristics. Thus, it poses a challenge to scale those up in a model grid cell (Schaudt and Dickinson, 2000) in atmospheric transport models. Using remote sensing, robust scaling of these parameter values is achieved, which could be used to acquire representative values in a model grid cell (Tian et al., 2011). However, addressing the issue of a model's structural uncertainty in a detailed manner was outside the scope of this paper.

The values of the eight model parameters, covering four meteorological $\left(U, u_{*}, L_{\mathrm{O}}\right.$, and $\left.\mathrm{RH}\right)$ and four canopy morphological $\left(z_{0}, d, h\right.$, and LAI) properties, used in the Monte Carlo simulations were assumed to be uniformly distributed because their true distributions were unknown. It is emphasized that these parameters are not all necessarily independent; $z_{0}$ and $d$ are functions of the surface characteristics (Zhang and Shao, 2014; Shao and Yang, 2005, 2008). Considering these underlying assumptions, the uncertainties in modeled $V_{\mathrm{d}}$ reported in this paper should be viewed as the effect of the chosen parameter PDFs on the output uncertainty. The uncertainty bounds (i.e., the central $90 \%$ values) reported in Table 9 could be treated as a metric of the quality of the modeled outputs. The normalized uncertainties reported in this study are a useful indicator to assess the overall performance of a model for four particle modes (seven particle sizes) across five LUCs.

We applied Sobol' sensitivity analysis to identify the most influential parameter(s) of the five parameterizations. Parameter rankings achieved using the Sobol' first-order indices for different models provide a robust evaluation of the models' sensitivity by varying a set of input parameters within their plausible ranges. It is emphasized that a local sensitivity analysis such as OAT could lead to incomplete or misleading inference of the parameter sensitivity on the model's output because assumptions of model linearity are not always justified for dry deposition parameterizations due to their complex formulations.

The Sobol' sensitivity rankings presented in Table 11 can be used for intercomparison between models' parameter sensitivity. Over rough surfaces, for nucleation size particles (e.g., $d_{\mathrm{p}}=0.001 \mu \mathrm{m}$ ), $u_{*}$ is the most sensitive parameter for Z01, PZ10, KS12, and ZH14 parameterizations. As particle size increases from 0.001 to $1.0 \mu \mathrm{m}$, except for the PZ10 scheme and for $1.0 \mu \mathrm{m}$ for grass in KS12 scheme, $u_{*}$ remains the most influential parameter. This finding is in accordance with previous studies (Zhang et al., 2001; Zhang and $\mathrm{He}, 2014)$ that show that dry deposition velocities for atmospheric particles are greatly influenced by friction velocity. We note that, in the PZ10 scheme, LAI and $L_{\mathrm{O}}$ are the two most commonly found sensitive parameters for $d_{\mathrm{p}}=0.001$ to $1.0 \mu \mathrm{m}$ for rough surfaces. As seen from the parameter rankings (Table 11), for $d_{\mathrm{p}}=10 \mu \mathrm{m}$ in the Z01, PZ10, KS12, ZH14 schemes, RH is the most influential factor. We postulate that with particle growth, high humidity may have a significant effect on coarse mode particles, and as a result, other model input parameters become less sensitive. The parameter ranking of the PZ10 scheme for deciduous forest shows that $L_{\mathrm{O}}$ is the most influential parameter. Similarly, for conif- 
erous forest, $L_{\mathrm{O}}$ is found to be one of the most sensitive parameters for most particle sizes. One possible reason for this finding could be the interdependency of the particle mixing length parameter and $L_{\mathrm{O}}$ in the PZ10 scheme. Indeed, the mixing length indirectly relates to particle collection efficiencies in the PZ10 parameterization (see Eqs. 18, 25, and 26). The rankings of the $\mathrm{Z} 01$ and $\mathrm{ZH} 14$ parameters are nearly identical for rough and smooth surfaces. This finding is not surprising given that these two parameterizations were developed by applying similar assumptions.

In general, dry deposition parameterizations developed for different particle size ranges and surfaces vary widely in terms of their complexity in model structure. The complexity in their numerical formulations often depends on the purpose (e.g., operational or research) of the model development (Petroff et al., 2008a). Comparing two previously developed one-dimensional aerosol deposition models for broadleaf and coniferous canopies (see details in Petroff et al., 2008b, 2009) with the PZ10 parameterization, Petroff and Zhang (2010) argued that the mathematical formulations in those models are too complex and require numerous input parameters for implementation in aerosol transport models. Following this hypothesis, we attempt to qualitatively evaluate the relative complexity of the five dry deposition parameterizations tested in this study for incorporation into atmospheric transport models.

Of the five parameterizations, we note that the model structure of the PZ10 is relatively more complex than that of the Z01, ZH14, and ZS14 parameterizations. The complexity of the KS12 parameterization tends to be different by a large degree between rough (i.e., vegetative canopies and snow) and smooth (i.e., water) surfaces. The ZS14 formulation (Eqs. 51-63) is of comparable complexity to the rough surface formulation in the KS12 parameterization (Eqs. 3545), and these parameterizations can be viewed as moderately complex. The formulation of the Z01 parameterization can be viewed as moderately complex as well. In this parameterization, three processes (Brownian diffusion, interception, and impaction) were parameterized using Eqs. (8)-(14) to describe the particle deposition at the collection surface. We claim that the KS12 parameterization for smooth surfaces is the most complex of the five models. This is mainly because it requires solving the dimensionless dry deposition velocity profiles over smooth surfaces using an analytical approach, which can be complex and computationally expensive.

A direct qualitative comparison of the relative complexities of the major process terms in the PZ10 and Z01 parameterizations is possible because both of these parameterizations are resistance based (i.e., expressions of $V_{\mathrm{d}}$ in Eqs. 2 and 16 are of similar forms). It is evident from Eqs. (19)-(31) that the formulations in the PZ10 parameterization to compute the three surface collection process terms are relatively complex as compared to those in the Z01 parameterization. In the ZH14 parameterization (a resistance-based scheme as well), these process terms are not explicitly parameterized. Presumably, by incorporating a large number of LUCdependent constants to compute surface deposition velocity using Eqs. (46)-(50), simplifications were made possible to the ZH14 parameterization. The use of fitting parameters to account for poorly understood dry deposition processes in parameterizations is not uncommon. Due to the complex nature and inadequate understanding of the particle collection processes to leaf surfaces, suggestions were made to treat particle deposition on vegetative surfaces in a simplified manner using empirically derived fitting parameters (Petroff et al., 2008a). Consequently, Petroff and Zhang (2010) also introduced a large number of artificial parameters to account for characteristic length and orientation of the canopy obstacle, and different LUCs to parameterize the particle collection efficiencies (e.g., due to Brownian diffusion, interception, turbulent and inertial impaction). Based on these considerations and those in the previous paragraph, we claim that the ZH14 is the simplest of the five parameterizations.

\section{Conclusions}

In terms of overall performance for incorporation in atmospheric transport models, we suggest that parameterization accuracy and uncertainty should be considered jointly, while, based on our findings, sensitivity of the model input parameters should be treated separately for each dry deposition parameterization. The paper presents a comprehensive evaluation of the performance of five parameterizations in terms of their accuracy, model output uncertainty, and parameter sensitivity. Based on the results, it is evident that the ZH14 parameterization is the most accurate for four of the five LUCs (grass, deciduous forest, water, and ice/snow surfaces) and second most accurate for the fifth LUC (coniferous forest). Of the five parameterizations, the uncertainty range for the ZH14 (11-20\%) has the lowest upper bound across the five LUCs for particle size ranging from 0.005 to $2.5 \mu \mathrm{m}$. In terms of the lower bound of the uncertainty range, the ZH14 is second to the Z01 (10-30\%) parameterization. We demonstrated that the Sobol' sensitivity analysis can be successfully applied to dry deposition models to rank the input parameters by taking into account the complex interactions between them. One could argue that, if the different models exhibited greatest sensitivities to different parameters, and those parameters were more uncertain, the models exhibiting greatest sensitivity to the least certain parameters would be the most uncertain. In this way, sensitivity plays a potential role in determining which model is better. However, because our results showed that all models were most sensitive to $u_{*}$, or, at large size, RH, sensitivity does not end up playing a role in assigning which model is best. We also note that accurate measurement of $u_{*}$ is extremely challenging (Andreas, 1992; Weber, 1999), and there exists ambiguity in its definition in boundary-layer meteorology (Weber, 1999). 
The large dispersion in the parameterizations' accuracy may indicate that despite considerable efforts in developing sophisticated process-based dry deposition models, there remain major gaps in our understanding of the dry deposition process. Another possible explanation for the large dispersion may be that it is significantly caused by measurement uncertainties, which were not addressed in this paper. However, intervariability in modeled deposition velocities is not uncommon, as pointed out by Ruijgrok et al. (1995) in an intercomparison study of several earlier dry deposition models. We emphasize that the accuracy results presented in this paper should be discussed in terms of the locations in which the parameterization accuracy has been evaluated against measurements for the five LUCs (Table 1; Fig. 1).

The results from the uncertainty analysis using the Monte Carlo simulations on the size-segregated particles should be of interest to atmospheric transport modelers as well as to the scientific community interested in quantifying the uncertainty bounds in the atmospheric deposition fluxes of pollutants to ecosystems using concentration data from monitoring stations. This is because, until now, uncertainties in modeled $V_{\mathrm{d}}$ for size-segregated particles for a suite of currently available dry deposition parameterizations have been unavailable. We stress that future work on probabilistic uncertainty analysis should focus on quantifying uncertainties for additional LUCs than those covered in this study. One of the major limitations of our uncertainty analysis approach is the assumption of uniform distribution of all imprecise model input parameters. To address this limitation, accurate information on the input parameter PDFs is needed.

With the help of field observations, and improved theoretical knowledge of dry deposition, the Sobol' parameter rankings could be used to fine-tune dry deposition models to better account for processes that are currently lacking or poorly parameterized. Future work should focus on estimating higher-order (i.e., second-order and total-order) Sobol' indices. Such indices would be useful for model developers interested in understanding the joint influence of multiple input parameters on the modeled deposition velocities.

Based on the qualitative evaluation of relative complexity of the five parameterizations, we suggest that the model structure of the ZH14 parameterization is the least complex. After reviewing over 100 air quality models, Kouznetsov and Sofiev (2012) reported that resistance-based approaches are extensively implemented in most of those models. Thus, in practice, it may be preferable to use a relatively simple parameterization over a complex (and potentially computationally expensive) one, if the accuracy and uncertainty of the model justify it. Based on these criteria (i.e., accuracy, uncertainty, and complexity), we propose that, of the five parameterizations we tested, the ZH14 parameterization is currently superior for incorporation into atmospheric transport models.
Code availability. The $\mathrm{R}$ scripts used in this study are available in the Supplement and can be found online at https://osf.io/a6q97/. R version 3.2.4 was used to create the scripts. A similar or higher version of $\mathrm{R}$ is required to run the scripts. The codes can be used, distributed, and reproduced for all non-commercial use under the terms of the Creative Commons - Attribution-NonCommercial 3.0 Unported license (http://creativecommons.org/licenses/by-nc/3.0/), provided the original work is properly cited.

\section{The Supplement related to this article is available online at https://doi.org/10.5194/gmd-10-3861-2017- supplement.}

Competing interests. The authors declare that they have no conflict of interest.

Acknowledgements. This project was funded by the US National Science Foundation's Coupled Natural-Human System Program through award no. 1313755.

Edited by: Jason Williams

Reviewed by: Bruce Hicks and Ali Oskouie

\section{References}

Alcamo, J. and Bartnicki, J.: A framework for error analysis of a long-range transport model with emphasis on parameter uncertainty, Atmos. Environ., 21, 2121-2131, 1987.

Allen, A., Harrison, R., and Nicholson, K.: Dry deposition of fine aerosol to a short grass surface, Atmos. Environ. A-Gen., 25, 2671-2676, 1991.

Andreas, E. L.: Uncertainty in a Path-averaged Measurement of the Friction Velocity $u$, J. Appl. Meteorol., 31, 1312-1321, 1992.

Beekmann, M. and Derognat, C.: Monte Carlo uncertainty analysis of a regional-scale transport chemistry model constrained by measurements from the atmospheric pollution over the Paris area (ESQUIF) campaign, J. Geophys. Res.-Atmos., 108, 8559, https://doi.org/10.1029/2003JD003391, 2003.

Bergin, M. S. and Milford, J. B.: Application of Bayesian Monte Carlo analysis to a Lagrangian photochemical air quality model, Atmos. Environ., 34, 781-792, 2000.

Bergin, M. S., Noblet, G. S., Petrini, K., Dhieux, J. R., Milford, J. B., and Harley, R. A.: Formal uncertainty analysis of a Lagrangian photochemical air pollution model, Environ. Sci. Technol., 33, 1116-1126, 1999.

Buzorius, G., Rannik, Ü., Mäkelä, J., Keronen, P., Vesala, T., and Kulmala, M.: Vertical aerosol fluxes measured by the eddy covariance method and deposition of nucleation mode particles above a Scots pine forest in southern Finland, J. Geophys. Res.Atmos., 105, 19905-19916, 2000.

Caffrey, P. F., Ondov, J. M., Zufall, M. J., and Davidson, C. I.: Determination of size-dependent dry particle deposition velocities with multiple intrinsic elemental tracers, Environ. Sci. Technol., 32, 1615-1622, 1998. 
Chen, L., Rabitz, H., Considine, D. B., Jackman, C. H., and Shorter, J. A.: Chemical reaction rate sensitivity and uncertainty in a twodimensional middle atmospheric ozone model, J. Geophys. Res.Atmos., 102, 16201-16214, 1997.

Cherin, N., Roustan, Y., Musson-Genon, L., and Seigneur, C.: Modelling atmospheric dry deposition in urban areas using an urban canopy approach, Geosci. Model Dev., 8, 893-910, https://doi.org/10.5194/gmd-8-893-2015, 2015.

Contini, D., Donateo, A., Belosi, F., Grasso, F., Santachiara, G., and Prodi, F.: Deposition velocity of ultrafine particles measured with the Eddy-Correlation Method over the Nansen Ice Sheet (Antarctica), J. Geophys. Res.-Atmos., 115, D16202, https://doi.org/10.1029/2009JD013600, 2010.

Derwent, R. and Hov, Ø.: Application of sensitivity and uncertainty analysis techniques to a photochemical ozone model, J. Geophys. Res.-Atmos., 93, 5185-5199, 1988.

Donateo, A. and Contini, D.: Correlation of dry deposition velocity and friction velocity over different surfaces for $\mathrm{PM}_{2.5}$ and particle number concentrations, Advances in Meteorology, 2014, https://doi.org/10.1155/2014/760393, 2014.

Duan, B., Fairall, C., and Thomson, D.: Eddy correlation measurements of the dry deposition of particles in wintertime, J. Appl. Meteorol., 27, 642-652, 1988.

Efron, B. and Tibshirani, R. J.: An introduction to the bootstrap, CRC press, Boca Raton, USA, 1994.

Feng, J.: A size-resolved model and a four-mode parameterization of dry deposition of atmospheric aerosols, J. Geophys. Res.Atmos., 113, D12201, https://doi.org/10.1029/2007JD009004, 2008.

Gallagher, M., Beswick, K., Duyzer, J., Westrate, H., Choularton, T., and Hummelshøj, P.: Measurements of aerosol fluxes to Speulder forest using a micrometeorological technique, Atmos. Environ., 31, 359-373, 1997.

Gaman, A., Rannik, Ü., Aalto, P., Pohja, T., Siivola, E., Kulmala, M., and Vesala, T.: Relaxed eddy accumulation system for sizeresolved aerosol particle flux measurements, J. Atmos. Ocean. Tech., 21, 933-943, 2004.

Giorgi, F.: A particle dry-deposition parameterization scheme for use in tracer transport models, J. Geophys. Res.-Atmos., 91, 9794-9806, 1986.

Gould, T. and Davidson, C.: Variability and uncertainty in particle dry deposition modelling, Precipitation Scavenging and Atmosphere-Surface Exchange Processes, Hemisphere, Publ., Washington, DC, USA, 1125-1142, 1992.

Grönholm, T., Launiainen, S., Ahlm, L., Mårtensson, E., Kulmala, M., Vesala, T., and Nilsson, E.: Aerosol particle dry deposition to canopy and forest floor measured by two-layer eddy covariance system, J. Geophys. Res.-Atmos., 114, D04202, https://doi.org/10.1029/2008JD010663, 2009.

Gronlund, A., Nilsson, D., Koponen, I. K., Virkkula, A., and Hansson, M. E.: Aerosol dry deposition measured with eddycovariance technique at Wasa and Aboa, Dronning Maud Land, Antarctica, Ann. Glaciol., 35, 355-361, 2002.

Hanna, S. R., Chang, J. C., and Fernau, M. E.: Monte Carlo estimates of uncertainties in predictions by a photochemical grid model (UAM-IV) due to uncertainties in input variables, Atmos. Environ., 32, 3619-3628, 1998.

Hanna, S. R., Lu, Z., Frey, H. C., Wheeler, N., Vukovich, J., Arunachalam, S., Fernau, M., and Hansen, D. A.: Uncertainties in predicted ozone concentrations due to input uncertainties for the UAM-V photochemical grid model applied to the July 1995 OTAG domain, Atmos. Environ., 35, 891-903, 2001.

Heinonen, M.: A comparison of humidity standards at seven European national standards laboratories, Metrologia, 39, 303, https://doi.org/10.1088/0026-1394/39/3/7, 2002.

Held, A., Brooks, I. M., Leck, C., and Tjernström, M.: On the potential contribution of open lead particle emissions to the central Arctic aerosol concentration, Atmos. Chem. Phys., 11, 3093 3105, https://doi.org/10.5194/acp-11-3093-2011, 2011a.

Held, A., Orsini, D. A., Vaattovaara, P., Tjernström, M., and Leck, C.: Near-surface profiles of aerosol number concentration and temperature over the Arctic Ocean, Atmos. Meas. Tech., 4, 1603-1616, https://doi.org/10.5194/amt-4-1603-2011, $2011 \mathrm{~b}$.

Hicks, B. B.: On estimating dry deposition rates in complex terrain, J. Appl. Meteorol. Clim., 47, 1651-1658, 2008.

Hicks, B. B., Baldocchi, D., Meyers, T., Hosker, R., and Matt, D.: A preliminary multiple resistance routine for deriving dry deposition velocities from measured quantities, Water Air Soil Poll., 36, 311-330, 1987.

Hicks, B. B., Saylor, R. D., and Baker, B. D.: Dry deposition of particles to canopies - A look back and the road forward, J. Geophys. Res.-Atmos., 121, 14691-14707, https://doi.org/10.1002/2015JD024742, 2016.

Högström, U. and Smedman, A.-S.: Accuracy of sonic anemometers: laminar wind-tunnel calibrations compared to atmospheric in situ calibrations against a reference instrument, Bound.-Lay. Meteorol., 111, 33-54, 2004.

Ibrahim, M., Barrie, L., and Fanaki, F.: An experimental and theoretical investigation of the dry deposition of particles to snow, pine trees and artificial collectors, Atmos. Environ., 17, 781-788, 1983.

IPCC: Third assessment report, Cambridge University Press. Volumes I (The Scientific Basis), II (Impacts, Adaptation, and Vulnerability) and III (Mitigation), Cambridge, UK and New York, USA, 2001.

Katul, G., Grönholm, T., Launiainen, S., and Vesala, T.: Predicting the dry deposition of aerosol-sized particles using layer-resolved canopy and pipe flow analogy models: Role of turbophoresis, J. Geophys. Res.-Atmos., 115, D12202, https://doi.org/10.1029/2009JD012853, 2010.

Kouznetsov, R. and Sofiev, M.: A methodology for evaluation of vertical dispersion and dry deposition of atmospheric aerosols, J. Geophys. Res.-Atmos., 117, D01202, https://doi.org/10.1029/2011JD016366, 2012.

Lamaud, E., Brunet, Y., Labatut, A., Lopez, A., Fontan, J., and Druilhet, A.: The Landes experiment: Biosphere-atmosphere exchanges of ozone and aerosol particles above a pine forest, J. Geophys. Res.-Atmos., 99, 16511-16521, 1994.

Larjavaara, M. and Muller-Landau, H. C.: Measuring tree height: a quantitative comparison of two common field methods in a moist tropical forest, Methods Ecol. Evol., 4, 793-801, 2013.

Lilburne, L. and Tarantola, S.: Sensitivity analysis of spatial models, Int. J. Geogr. Inf. Sci., 23, 151-168, 2009.

McMahon, T. and Denison, P.: Empirical atmospheric deposition-a survey, Atmos. Environ., 13, 571-585, 1979.

Mallet, V. and Sportisse, B.: Uncertainty in a chemistrytransport model due to physical parameterizations and numerical approximations: An ensemble approach applied to 
ozone modeling, J. Geophys. Res.-Atmos., 111, D01302, https://doi.org/10.1029/2005JD006149, 2006.

Matsuda, K., Fujimura, Y., Hayashi, K., Takahashi, A., and Nakaya, K.: Deposition velocity of $\mathrm{PM}_{2.5}$ sulfate in the summer above a deciduous forest in central Japan, Atmos. Environ., 44, 45824587, 2010.

Möller, U. and Schumann, G.: Mechanisms of transport from the atmosphere to the Earth's surface, J. Geophys. Res., 75, 30133019, 1970.

Muyshondt, A., Anand, N., and McFarland, A. R.: Turbulent deposition of aerosol particles in large transport tubes, Aerosol Sci. Tech., 24, 107-116, 1996.

Nemitz, E., Gallagher, M. W., Duyzer, J. H., and Fowler, D.: Micrometeorological measurements of particle deposition velocities to moorland vegetation, Q J. Roy. Meteor. Soc., 128, 22812300, 2002.

Neumann, H. and Den Hartog, G.: Eddy correlation measurements of atmospheric fluxes of ozone, sulphur, and particulates during the Champaign intercomparison study, J. Geophys. Res.-Atmos., 90, 2097-2110, 1985.

Nilsson, E. D. and Rannik, Ü.: Turbulent aerosol fluxes over the Arctic Ocean, 1. Dry deposition over sea and pack ice, J. Geophys. Res., 106, 32125-32137, 2001.

Noll, K. E., Jackson, M. M., and Oskouie, A. K.: Development of an atmospheric particle dry deposition model, Aerosol Sci. Tech., 35, 627-636, 2001.

Nossent, J., Elsen, P., and Bauwens, W.: Sobol'sensitivity analysis of a complex environmental model, Environ. Modell. Softw., 26, 1515-1525, 2011.

Oskouie, A. K., Noll, K. E., and Wang, H.-C.: Minimizing the effect of density in determination of particle aerodynamic diameter using a time of flight instrument, J. Aerosol Sci., 34, 501-506, 2003.

Pappenberger, F., Beven, K. J., Ratto, M., and Matgen, P.: Multimethod global sensitivity analysis of flood inundation models, Adv. Water Resour., 31, 1-14, 2008.

Petroff, A. and Zhang, L.: Development and validation of a size-resolved particle dry deposition scheme for application in aerosol transport models, Geosci. Model Dev., 3, 753-769, https://doi.org/10.5194/gmd-3-753-2010, 2010.

Petroff, A., Mailliat, A., Amielh, M., and Anselmet, F.: Aerosol dry deposition on vegetative canopies. Part I: review of present knowledge, Atmos. Environ., 42, 3625-3653, 2008a.

Petroff, A., Mailliat, A., Amielh, M., and Anselmet, F.: Aerosol dry deposition on vegetative canopies. Part II: A new modelling approach and applications, Atmos. Environ., 42, 3654-3683, 2008b.

Petroff, A., Zhang, L., Pryor, S. C., and Belot, Y.: An extended dry deposition model for aerosols onto broadleaf canopies, J. Aerosol Sci., 40, 218-240, 2009.

Pryor, S.: Size-resolved particle deposition velocities of sub-100 nm diameter particles over a forest, Atmos. Environ., 40, 6192-6200, 2006.

Pryor, S., Larsen, S. E., Sørensen, L. L., Barthelmie, R. J., Grönholm, T., Kulmala, M., Launiainen, S., Rannik, Ü., and Vesala, T.: Particle fluxes over forests: Analyses of flux methods and functional dependencies, J. Geophys. Res.-Atmos., 112, D07205, https://doi.org/10.1029/2006JD008066, 2007.
Pryor, S., Gallagher, M., Sievering, H., Larsen, S. E., Barthelmie, R. J., Birsan, F., Nemitz, E., Rinne, J., Kulmala, M., and Grönholm, T.: A review of measurement and modelling results of particle atmosphere-surface exchange, Tellus B, 60, 42-75, 2008.

Pryor, S., Barthelmie, R., and Hornsby, K.: Size-resolved particle fluxes and vertical gradients over and in a sparse pine forest, Aerosol Sci. Tech., 47, 1248-1257, 2013.

Rannik, Ü., Petäjä, T., Buzorius, G., Aalto, P., Vesala, T., and Kulmala, M.: Deposition velocities of nucleation mode particles into a Scots pine forest, Environmental and Chemical Physics, 22, 97-102, 2000.

Rannik, Ü., Zhou, L., Zhou, P., Gierens, R., Mammarella, I., Sogachev, A., and Boy, M.: Aerosol dynamics within and above forest in relation to turbulent transport and dry deposition, Atmos. Chem. Phys., 16, 3145-3160, https://doi.org/10.5194/acp16-3145-2016, 2016.

Richardson, A. D., Dail, D. B., and Hollinger, D.: Leaf area index uncertainty estimates for model-data fusion applications, Agr. Forest Meteorol., 151, 1287-1292, 2011.

Ruijgrok, W.: Uncertainty in models calculating the dry deposition of aerosols to forests, Nucleation and atmospheric aerosols, Deepak Publ., Hampton, USA, 481-485, 1992.

Ruijgrok, W., Tieben, H., and Eisinga, P.: The dry deposition of particles to a forest canopy: a comparison of model and experimental results, Atmos. Environ., 31, 399-415, 1997.

Ruijgrok, W., Davidson, C. I., and Nicholson, W.: Dry deposition of particles, Tellus B, 47, 587-601, 1995.

Saltelli, A. and Annoni, P.: How to avoid a perfunctory sensitivity analysis, Environ. Modell. Softw., 25, 1508-1517, 2010.

Saltelli, A., Annoni, P., Azzini, I., Campolongo, F., Ratto, M., and Tarantola, S.: Variance based sensitivity analysis of model output. Design and estimator for the total sensitivity index, Comput. Phys. Commun., 181, 259-270, 2010.

Schaudt, K. and Dickinson, R.: An approach to deriving roughness length and zero-plane displacement height from satellite data, prototyped with BOREAS data, Agr. Forest Meteorol., 104, 143$155,2000$.

Sehmel, G. A.: Particle and gas dry deposition: a review, Atmos. Environ., 14, 983-1011, 1980.

Sehmel, G. A. and Hodgson, W.: Model for predicting dry deposition of particles and gases to environmental surfaces, Battelle Pacific Northwest Labs., Richland, WA, USA, 1978.

Sehmel, G. A., Sutter, S., and Simpson, C.: Particle deposition rates on a water surface as a function of particle diameter and air velocity, Battelle Pacific Northwest Labs., Richland, WA, USA, 1974.

Seinfeld, J. and Pandis, S.: Atmospheric chemistry and physics: from air pollution to climate change, John Wiley \& Sons, Inc., New Jersey, USA, 2006.

Shao, Y. and Yang, Y.: A scheme for drag partition over rough surfaces, Atmos. Environ., 39, 7351-7361, 2005.

Shao, Y. and Yang, Y.: A theory for drag partition over rough surfaces, J. Geophys. Res.-Earth, 113, https://doi.org/10.1029/2007JF000791, 2008.

Slinn, W.: Predictions for particle deposition to vegetative canopies, Atmos. Environ., 16, 1785-1794, 1982.

Sobol', I. M.: Sensitivity estimates for nonlinear mathematical models, Math. Model. Comput. Exp., 1, 407-414, 1993. 
Stull, R. B.: An introduction to boundary layer meteorology, Springer Science \& Business Media, Dordrecht, the Netherlands, 2012.

Su, Z., Schmugge, T., Kustas, W., and Massman, W.: An evaluation of two models for estimation of the roughness height for heat transfer between the land surface and the atmosphere, J. Appl. Meteorol., 40, 1933-1951, 2001.

Tang, Y., Reed, P., Wagener, T., and van Werkhoven, K.: Comparing sensitivity analysis methods to advance lumped watershed model identification and evaluation, Hydrol. Earth Syst. Sci., 11, 793817, https://doi.org/10.5194/hess-11-793-2007, 2007.

Tatang, M. A., Pan, W., Prinn, R. G., and McRae, G. J.: An efficient method for parametric uncertainty analysis of numerical geophysical models, J. Geophys. Res.-Atmos., 102, 21925-21932, 1997.

Tian, X., Li, Z., Van der Tol, C., Su, Z., Li, X., He, Q., Bao, Y., Chen, E., and Li, L.: Estimating zero-plane displacement height and aerodynamic roughness length using synthesis of LiDAR and SPOT-5 data, Remote Sens. Environ., 115, 2330-2341, 2011.

Van Aalst, R. M.: Dry deposition of aerosol particles, edited by: Lee, D., Schneider, T., Grant, L., and Verkert, P., Aerosols, Lewis Publication, Chelsea, Michigan, USA, 933-949, 1986.

Van Werkhoven, K., Wagener, T., Reed, P., and Tang, Y.: Characterization of watershed model behavior across a hydroclimatic gradient, Water Resour. Res., 44, https://doi.org/10.1029/2007WR006271, 2008.

Venkatram, A. and Pleim, J.: The electrical analogy does not apply to modeling dry deposition of particles, Atmos. Environ., 33, 3075-3076, 1999.

Vong, R. J., Vickers, D., and Covert, D. S.: Eddy correlation measurements of aerosol deposition to short grass, Tellus B, 56, 105117, 2004.

Weber, R. O.: Remarks on the definition and estimation of friction velocity, Bound.-Lay. Meteorol., 93, 197-209, 1999.

Weidinger, T., Pinto, J., and Horváth, L.: Effects of uncertainties in universal functions, roughness length, and displacement height on the calculation of surface layer fluxes, Meteorol. Z., 9, 139$154,2000$.

Wesely, M. and Hicks, B.: A review of the current status of knowledge on dry deposition, Atmos. Environ., 34, 2261-2282, 2000.

Wesely, M., Hicks, B., Dannevik, W., Frisella, S., and Husar, R.: An eddy-correlation measurement of particulate deposition from the atmosphere, Atmos. Environ., 11, 561-563, 1977.
Wesely, M., Cook, D., and Hart, R.: Fluxes of gases and particles above a deciduous forest in wintertime, Bound.-Lay. Meteorol., 27, 237-255, 1983.

Williams, R. M.: A model for the dry deposition of particles to natural water surfaces, Atmos. Environ., 16, 1933-1938, 1982.

Wiman, B. L. and Ågren, G. I.: Aerosol depletion and deposition in forests - a model analysis, Atmos. Environ., 19, 335-347, 1985.

Wyers, G. and Duyzer, J.: Micrometeorological measurement of the dry deposition flux of sulphate and nitrate aerosols to coniferous forest, Atmos. Environ., 31, 333-343, 1997.

Yang, J.: Convergence and uncertainty analyses in Monte-Carlo based sensitivity analysis, Environ. Modell. Softw., 26, 444-457, 2011.

Yu, S., Eder, B., Dennis, R., Chu, S. H., and Schwartz, S. E.: New unbiased symmetric metrics for evaluation of air quality models, Atmos. Sci. Lett., 7, 26-34, 2006.

Zhang, J. and Shao, Y.: A new parameterization of particle dry deposition over rough surfaces, Atmos. Chem. Phys., 14, 1242912440, https://doi.org/10.5194/acp-14-12429-2014, 2014.

Zhang, L. and He, Z.: Technical Note: An empirical algorithm estimating dry deposition velocity of fine, coarse and giant particles, Atmos. Chem. Phys., 14, 3729-3737, https://doi.org/10.5194/acp-14-3729-2014, 2014

Zhang, L. and Vet, R.: A review of current knowledge concerning size-dependent aerosol removal, China Part., 4, 272-282, 2006.

Zhang, L., Gong, S., Padro, J., and Barrie, L.: A size-segregated particle dry deposition scheme for an atmospheric aerosol module, Atmos. Environ., 35, 549-560, 2001.

Zhang, L., Blanchard, P., Gay, D. A., Prestbo, E. M., Risch, M. R., Johnson, D., Narayan, J., Zsolway, R., Holsen, T. M., Miller, E. K., Castro, M. S., Graydon, J. A., Louis, V. L. St., and Dalziel, J.: Estimation of speciated and total mercury dry deposition at monitoring locations in eastern and central North America, Atmos. Chem. Phys., 12, 4327-4340, https://doi.org/10.5194/acp12-4327-2012, 2012.

Zufall, M. J., Davidson, C. I., Caffrey, P. F., and Ondov, J. M.: Airborne concentrations and dry deposition fluxes of particulate species to surrogate surfaces deployed in southern Lake Michigan, Environ. Sci. Technol., 32, 1623-1628, 1998. 